\title{
Article \\ Effect of the Functional Group Position in Functionalized Liquid Butadiene Rubbers Used as Processing Aids on the Properties of Silica-Filled Rubber Compounds
}

\author{
Donghyuk Kim ${ }^{1,+}$, Gyeongdong Yeom ${ }^{2,+}$, Hongil Joo ${ }^{3}$, Byungkyu Ahn ${ }^{4}$, Hyun-Jong Paik ${ }^{2, *}$, Heungbae Jeon ${ }^{3, *}$ \\ and Wonho Kim 1 ,*
}

Citation: Kim, D.; Yeom, G.; Joo, H.; Ahn, B.; Paik, H.-J.; Jeon, H.; Kim, W. Effect of the Functional Group Position in Functionalized Liquid Butadiene Rubbers Used as Processing Aids on the Properties of Silica-Filled Rubber Compounds.

Polymers 2021, 13, 2698

https://doi.org/10.3390/

polym 13162698

Academic Editor: Xavier Colom

Received: 19 July 2021

Accepted: 10 August 2021

Published: 12 August 2021

Publisher's Note: MDPI stays neutral with regard to jurisdictional claims in published maps and institutional affiliations.

Copyright: (c) 2021 by the authors. Licensee MDPI, Basel, Switzerland. This article is an open access article distributed under the terms and conditions of the Creative Commons Attribution (CC BY) license (https:// creativecommons.org/licenses/by/ $4.0 /)$.
1 School of Chemical Engineering, Pusan National University, Busan 46241, Korea; ehdgurzxc@gmail.com

2 Department of Polymer Science and Engineering, Pusan National University, Busan 46241, Korea; rudehd2012@gmail.com

3 Department of Chemistry, Kwangwoon University, Seoul 01897, Korea; jhi940307@naver.com

4 Hankook Tire \& Technology Co., Ltd. R\&D Center, Yuseong-gu, Daejeon 34127, Korea; bkahn8855@gmail.com

* Correspondence: hpaik@pusan.ac.kr (H.-J.P.); hbj@kw.ac.kr (H.J.); whkim@pusan.ac.kr (W.K.); Tel.: +82-51-510-3190 (W.K.)

+ Donghyuk Kim and Gyeongdong Yeom have equally contributed. Donghyuk Kim and Gyeongdong Yeom are Co-First-Authors.

Abstract: Recently, research conducted on tread compounds with liquid butadiene rubber (LqBR) have been conducted in the tire industry. In particular, the introduction of functional groups into LqBRs is expected to lower hysteresis loss caused by the free chain ends of LqBR. To study this, LqBRs with functional groups at different positions were synthesized. The occurrences of in-chain and chain-end functionalization of functionalized LqBRs (F-LqBRs) were confirmed, the microstructure and functionalization efficiency of F-LqBRs were calculated through the characterizations. This novel functionalization technology was beneficial not only to immobilizing the free chain ends of LqBRs to the surfaces of silica to decrease the number of free chain ends, but also chemically bonding the LqBR chains on the base polymer through a crosslinking reaction to enhance the filler-rubber interaction. The effects of the functional group position and number of the free chain ends on the physical properties and hysteresis of the compounds were investigated by partially replacing the treated distillate aromatic extract (TDAE) oil with LqBR in silica-filled rubber compounds. The results showed that compounds that had applied DF-LqBR with both end functionalization performed better, including improving the silica dispersion, higher extraction resistance, and lower rolling resistance, than other F-LqBRs compounds.

Keywords: liquid butadiene rubber; silica-filled compound; anionic polymerization; radical polymerization; rubber compounding

\section{Introduction}

Liquid butadiene rubber (LqBR) is widely used as a vulcanizable plasticizer in tires, plastics, printing inks, paints, coatings, and sealants [1]. Interest in LqBR has increased significantly since 1990, as it has been used to serve the purpose of plasticizers and cure coagents, as well as to improve the viscoelastic properties of tire treads in the rubber industry. In particular, research in the tire industry has significantly increased over the past decade, which can be confirmed by the significant increase in the number of patent applications related to liquid polymers [2].

Since 1995, European processing oil producers and tire manufacturers have developed processing aids to replace highly aromatic oil (distilled aromatic extract, DAE), which contains carcinogenic polycyclic aromatic hydrocarbons (PAHs). In fact, the use of DAE oils in tire manufacturing was banned in 2010, according to the EU REACH regulations. 
Therefore, oils with low PAH content, such as treated DAE (TDAE) oils, are used as alternative processing aids [3,4]. However, TDAE oil-applied vulcanizates have a disadvantage in that the physical properties of vulcanizates deteriorate owing to the migration of TDAE oil to the tire surface over time $[5,6]$. To address these issues, new processing aids with low $\mathrm{T}_{\mathrm{g}}$, non-PAHs, and no migration problem have been suggested. Accordingly, the demand and interest in LqBRs have gradually increased.

Along with various attempts to apply LqBR as a processing aid in the manufacture of passenger car tires, application technologies have been gradually developed. Kuraray Co., Ltd. in Japan (2017), Sumitomo Rubber Industries in Japan (2018), and Continental AG in Germany (2015) improved the abrasion resistance, snow traction, and viscoelastic performance at low temperatures by applying non-functionalized LqBR (NF-LqBR) with low vinyl content to winter tire compounds $[7,8]$. Hirata et al., applied commercialized non-functionalized liquid rubbers as processing aids to carbon black-filled NR compounds, thereby overcoming the processability and migration problems [9]. However, the problem of hysteresis caused by the free chain ends of LqBRs should be solved to expand the application of LqBRs in passenger car tires.

With interest in non-DAE plasticizers, tire manufacturers led by Michelin conducted studies using silica as a reinforcing filler to replace carbon black in order to reduce greenhouse gas emissions in 1993 [10]. Due to the fact that the silica surface is significantly more reactive than that of hydrophobic carbon black, the use of silane coupling agents was necessary for compounds to achieve a desirable balance of traction and low rolling resistance. Therefore, this switch in filler technology was responsible for increasing interest in the introduction of functional groups into polymer chains [11-13].

Based on these technologies, silane-functionalized LqBRs have been commercialized since 2017 [14,15], and studies on their application to tire compounds have been reported [16-18]. Salort et al., reported that low-molecular-weight silane-functionalized LqBRs can be crosslinked to the base polymer by sulfur through higher molecular-weight structure formation by self-condensation [2]. Kim et al., reported that silane-functionalized LqBRs can perform a role similar to that of a silane coupling agent in the compound because the ethoxysilyl group not only reacts with the silanol group of silica, but also crosslinks with the base polymer by consuming sulfur [19]. In addition, when processing oils and NF-LqBRs are replaced by silane-functionalized LqBRs, hysteresis can be greatly reduced owing to the decrease in the chain mobility due to the functional groups and the decrease in the number of free chain ends. Moreover, Hogan et al., reported that additional modifications of LqBR with alkoxy groups, amino groups, cyano groups, sulfonyl groups, epoxy groups, and halogen atoms further improved performance, as it can form chemical bonds with silanol groups present on the silica surface [11-13].

However, most previous studies used commercialized functionalized-LqBRs (F-LqBRs) instead of in-house synthesized LqBRs, so the structure of LqBRs was limited with respect to the control of molecular weight, vinyl content, and functionalization. Due to this limitation, it was difficult to explain the underlying reason for the mechanism of F-LqBRs in the compounds and physical properties. It is a technical problem in the synthesis of F-LqBRs that needs to be investigated. The synthesis technique of the introduction of functional groups into LqBRs used in this article is very rare. There are few related studies on this. In addition, there is still a lack of research on the effect of the functional group position and number of the free chain ends of F-LqBRs on the physical properties and hysteresis of the compounds. Moreover, many patents describe the performances of the tire tread compound that include F-LqBRs. However, there are no publications that describe the reasons for the observed performances. A better understanding of it would lead to more effective developments on the structure of F-LqBRs and applications in tire tread compounds. Therefore, the goal of the present investigation is to provide more understanding about the effects of F-LqBRs in tread compounds: (i) influence of the functional group position in F-LqBRs on silica hydrophobation and physical properties; (ii) the effect of the number of free chain ends of F-LqBRs on the hysteresis of the compounds. 
To address these problems, in this study, LqBRs with low vinyl content and functional groups at different positions, such as NF-LqBR, one-chain end-functionalized LqBR (OFLqBR), center-functionalized LqBR (CF-LqBR), and di-functionalized LqBR (DF-LqBR), were synthesized using anionic and radical polymerization. In addition, silica-filled rubber compounds were manufactured by applying LqBRs as processing aids to replace TDAE oils, and the effects of the functional group position and number of free chain ends of LqBRs on the performance of tire tread compounds were confirmed by evaluating the physical properties. Moreover, the mechanism and physics of the structure formation and the relationship with the properties were analyzed in detail. The presented results are expected to provide a foundation for the optimal design of LqBR structure and selection of LqBRs required for the manufacture of tire tread compounds to which LqBRs are applied.

\section{Materials and Methods}

\subsection{Materials}

2.1.1. Synthesis of 4,4'-(diazene-1,2-diyl)bis-(4-cyano-N-(3-triethoxysilyl)propyl)pentanamide (Difunctional Initiator)

Triethylamine (TEA, 98\%, Duksan General Chemical Co., Seoul, Korea), 4,4'-azobis(4cyanovaleric acid) (98\%, Sigma-Aldrich Corp., Seoul, Korea), (3-aminopropyl) triethoxysilane (98\%, Sigma-Aldrich Corp., Seoul, Korea), and ethyl chloroformate (97\%, SigmaAldrich Corp., Seoul, Korea) were used as reagents. Tetrahydrofuran (THF, 99\%, Duksan General Chemical Co., Seoul, Korea) was used as a solvent. For purification, $n$-hexane (95\%, Duksan General Chemical Co., Seoul, Korea) and diethyl ether (99\%, Daejung Chemicals \& Metals Co., Siheung, Korea) were used.

\subsubsection{Polymerization}

All materials used in the polymerization were purged with nitrogen, and cyclohexane (99\%, Samchun Chemical Co., Seoul, Korea) and tetrahydrofuran (THF, 99\%, Samchun Chemical Co., Seoul, Korea) were used as organic solvents. $N$-butyl lithium (2.0 M in cyclohexane, Sigma-Aldrich Corp., Seoul, Korea) and a difunctional initiator (self-made in laboratory) were used as initiators for anionic and radical polymerization. Anisole (99\%, Samchun Chemical Co., Seoul, Korea) was used as a polar modifier to control the vinyl content, and 1,3-butadiene (Kumho Petrochemical Co., Daejeon, Korea) was used as a monomer. Tetraethyl orthosilicate (TEOS, 98\%, Sigma-Aldrich Corp., Seoul, Korea) and 3-chloropropyltriethoxysilane (CPTES, 97\%, Sigma-Aldrich Corp., Seoul, Korea) were used as coupling agents, and $n$-octyl alcohol (99\%, Yakuri Pure Chemicals Co. Ltd., Kyoto, Japan) was used as a terminating agent.

\subsubsection{Compounding}

SSBR (SOL-5220M, Kumho Petrochemical Co. Daejeon, Korea, styrene content: $26.5 \mathrm{wt} \%$, vinyl content: $26 \mathrm{wt} \%$, non-oil extended) and high-cis butadiene rubber (CB24, Lanxess Chemical Industry Co., Ltd., Cologne, Germany; cis content: $96 \mathrm{wt} \%$ ) were used as base polymers. Silica (ZEOSIL 195MP, Solvay Silica Korea Co., Ltd., Gunsan, Korea) was used as a filler, and X50-S (Evonik Industries AG, Essen, Germany; bis-[3(triethoxysilyl)propyl]tetrasulfide (TESPT) 50\%, carbon black N330 50\%) was used as a silane coupling agent. Moreover, TDAE oil (Kukdong Oil \& Chemicals Co., Yangsan, Korea) was used as a processing aid for mixing. $\mathrm{ZnO}$ and stearic acid (both from SigmaAldrich Corp., Seoul, Korea) were used as activators, and N-(1,3-dimethylbutyl)-N-phenylp-phenylenediamine (6PPD, Kumho Petrochemical Co., Daejeon, Korea) was used as an antioxidant in the compound. Sulfur (Daejung Chemicals \& Metals Co., Siheung, Korea) was used as a crosslinking agent. N-cyclohexyl benzothiazole-2-sulfenamide (CBS, 98\%, Tokyo Chemical Industry Co. Ltd., Tokyo, Japan) and 1,3-diphenylguanidine (DPG 98\%, Tokyo Chemical Industry Co. Ltd., Tokyo, Japan) were used as cure accelerators. 


\subsection{Measurements}

\subsubsection{Gel Permeation Chromatography (GPC)}

The molecular weight and the molecular weight distribution were measured using a gel permeation chromatography (GPC) system (Shimadzu, Kyoto, Japan). The GPC system consisted of a solvent delivery unit, a refractive index detector, and three types of Styragel columns: HT 6E $(10 \mu \mathrm{m}, 7.8 \mathrm{~mm} \times 300 \mathrm{~mm})$, HMW 7 column $(15-20 \mu \mathrm{m}$, $7.8 \mathrm{~mm} \times 300 \mathrm{~mm})$, and HMW $6 \mathrm{E}$ column $(15-20 \mu \mathrm{m}, 7.8 \mathrm{~mm} \times 300 \mathrm{~mm})$. The measured molecular weight was corrected using a polystyrene standard sample (Easi Cal PS-1 standard, Agilent Technologies, Santa Clara, CA, USA).

\subsubsection{Proton Nuclear Magnetic Resonance Spectroscopy $\left({ }^{1} \mathrm{H}\right.$ NMR)}

The vinyl content in LqBR was evaluated using proton nuclear magnetic resonance spectroscopy $\left({ }^{1} \mathrm{H}\right.$ NMR; Varian, Unity Plus 300 spectrometer, Garden State Scientific, Morristown, NJ, USA). LqBRs were dissolved in a $5 \mathrm{~mm}$ NMR tube at a concentration of $15 \mathrm{mg} / \mathrm{mL}$ using deuterochloroform $\left(\mathrm{CDCl}_{3}\right.$, Cambridge Isotope Laboratories, Inc., Andover, MA, USA) as a solvent.

\subsubsection{Differential Scanning Calorimetry (DSC)}

The glass transition temperature $\left(\mathrm{T}_{\mathrm{g}}\right)$ was determined using a differential scanning calorimeter (DSC-Q10, TA Instruments, New Castle, DE, USA). The curves for samples (3-6 mg) were obtained by heating the sample from -120 to $-20^{\circ} \mathrm{C}$ at a heating rate of $10^{\circ} \mathrm{C} / \mathrm{min}$ under a nitrogen atmosphere.

\subsubsection{Payne Effect}

A rubber processing analyzer (RPA2000, Alpha Technologies, Hudson, OH, USA) was used to evaluate the silica dispersion and filler-filler interaction of the compound. The storage modulus $\left(\mathrm{G}^{\prime}\right)$ of the uncured compound was measured at a temperature of $60{ }^{\circ} \mathrm{C}$ in the range of $0.01-40.04 \%$ strain. In the low-strain region, the $\mathrm{G}^{\prime}$ value is large because the silica agglomerates are not destroyed. In contrast, with the agglomerate destruction in the high-strain region, the $G^{\prime}$ value decreases. Therefore, the change in $G^{\prime}$, that is, $\Delta G^{\prime}$ $\left(G^{\prime}\right.$ at $0.28 \%-G^{\prime}$ at $\left.40.04 \%\right)$ is called the Payne effect, which indicates the degree of the filler-filler interaction.

\subsubsection{Mooney Viscosity}

A Mooney viscometer (Vluchem IND Co., Seoul, Korea) was used to evaluate the processability of rubber by measuring the torque when the rotor rotated in a space filled with an uncured rubber compound according to ASTM D1646. The rotation speed of the rotor was set to $2 \mathrm{rpm}$, and the temperature was set to $100^{\circ} \mathrm{C}$. The torque value was measured by rotating the rotor for 4 min after preheating for $1 \mathrm{~min}$.

\subsubsection{Cure Characteristics}

To measure the curing characteristics of the compound, a moving die rheometer (MDR, Myung Ji Co., Seoul, Korea) was operated for $30 \mathrm{~min}$, maintaining a vibration angle of $\pm 1^{\circ}$ and a temperature of $160^{\circ} \mathrm{C}$. Meanwhile, the minimum torque $\left(\mathrm{T}_{\min }\right)$, maximum torque $\left(\mathrm{T}_{\max }\right)$, scorch time $\left(\mathrm{t}_{10}\right)$, and optimal cure time $\left(\mathrm{t}_{90}\right)$ were measured.

\subsubsection{Solvent Extraction and Crosslink Density}

The crosslink density is defined as the number of crosslink points in vulcanizates. If the crosslink density is increased, the molecular weight between crosslink points decreases, and the number of crosslink points increases. In swelling tests, the higher the crosslink density, the lower the number of solvent molecules that can permeate between the crosslinked rubber chains, resulting in relatively less swelling. Vulcanizates with dimensions of $10 \mathrm{~mm} \times 10 \mathrm{~mm} \times 2 \mathrm{~mm}$ were weighed and immersed in tetrahydrofuran (THF, 99\%, Samchun Chemical Co., Seoul, Korea) and $n$-hexane (95\%, Samchun Chemi- 
cal Co., Seoul, Korea) at $25^{\circ} \mathrm{C}$ for 2 days to remove organic additives from the sample. Subsequently, the weight was measured after the sample was dried at $25^{\circ} \mathrm{C}$ for 1 day to determine the mass fraction of the extracted organic additive. The weight of the sample immersed and swollen in a toluene solvent for 1 day at room temperature $\left(25^{\circ} \mathrm{C}\right)$ was measured after measuring the weight of the dry sample to calculate the total crosslink density. Moreover, the total crosslink density and the average molecular weight between crosslink points, $\mathrm{M}_{\mathrm{c}}$, were calculated using the Flory-Rehner equation [20-23]:

$$
v=\frac{1}{2 M_{c}}=-\frac{\ln \left(1-v_{r}\right)+v_{r}+\chi v_{r}^{2}}{2 \rho V_{s}\left(v_{r}^{\frac{1}{3}}-v_{r} / 2\right)},
$$

where $v$ is the crosslink density $(\mathrm{mol} / \mathrm{g}), M_{c}$ is the average molecular weight between crosslink points $(\mathrm{g} / \mathrm{mol}), v_{r}$ is the volume fraction of rubber in the swollen gel at equilibrium given by Equation (2), vs. is the molar volume of the solvent $\left(\mathrm{cm}^{3} / \mathrm{mol}\right), \rho$ is the density of the rubber sample $\left(\mathrm{g} / \mathrm{cm}^{3}\right)$, and $\chi$ is the polymer-solvent interaction parameter.

$$
v_{r}=\frac{\frac{w_{\text {dry }}-w_{\text {filler }}}{\rho_{\text {rubber }}}}{\frac{w_{\text {dry }}-w_{\text {filler }}}{\rho_{\text {rubber }}}+\frac{w_{\text {swollen }}-w_{\text {dry }}}{\rho_{\text {solvent }}}}
$$

In this equation, $w_{\text {dry }}$ is the weight of the dry sample, $w_{\text {filler }}$ is the weight of the filler in the dry sample, $w_{\text {swollen }}$ is the weight of the swollen sample, $\rho_{\text {rubber }}$ is the density of the rubber, and $\rho_{\text {solvent }}$ is the density of the solvent.

$$
\chi=0.34+\frac{v_{0}}{R T}\left(\delta_{p}-\delta_{s}\right)^{2} .
$$

Here, $v_{0}$ is the molar volume of the solvent, $\delta_{p}$ is the solubility parameter of the polymer, and $\delta_{s}$ is the solubility parameter of the solvent.

\subsubsection{Mechanical Properties}

A $100 \mathrm{~mm}$ (length) $\times 25 \mathrm{~mm}$ (width) dumbbell-shaped specimen that was prepared according to ATSM D 412 was measured at a speed of $500 \mathrm{~mm} / \mathrm{min}$ using a universal testing machine (UTM, KSU-05M-C, KSU Co., Ansan, Korea) to measure the mechanical properties (tensile strength, modulus, and elongation at break) of the vulcanizates.

\subsubsection{Abrasion Resistance}

The abrasion resistance was measured according to DIN 53516 using a Deutsche Industrie Normen (DIN) abrasion tester. The specimen was prepared in a cylindrical shape with a diameter of $16 \mathrm{~mm}$ and a thickness of $8 \mathrm{~mm}$. The mass reduction after moving the specimen $40 \mathrm{~m}$ across the surface of an abrasive sheet mounted on a cylindrical drum revolving at $40 \pm 1 \mathrm{rpm}$ was measured by applying a load of $5 \mathrm{~N}$.

\subsubsection{Viscoelastic Properties}

For the dynamic viscoelastic properties of the compound, the storage modulus $\left(\mathrm{G}^{\prime}\right)$, loss modulus $\left(\mathrm{G}^{\prime \prime}\right)$, and $\tan \delta$ were measured from -60 to $70{ }^{\circ} \mathrm{C}$ under a $10 \mathrm{~Hz}$ frequency at $0.5 \%$ strain using a strain-controlled rheometer (ARES-G2, TA Instrument, New Castle, DE, USA).

\subsection{Synthesis of 4,4'-(diazene-1,2-diyl)bis-(4-cyano-N-(3-triethoxysilyl)propyl)pentanamide (Difunctional Initiator)}

The synthesis of a difunctional initiator containing ethoxysilyl groups at both ends is shown in Scheme 1 [24]. $14 \mathrm{~g}$ ( $0.049 \mathrm{~mol}, 1$ equivalent) of 4,4-azobis(4-cyanovaleric acid) was dissolved in $300 \mathrm{~mL}$ of THF at room temperature $\left(25^{\circ} \mathrm{C}\right)$ under Ar condition. After stirring at $-78^{\circ} \mathrm{C}$ for $20 \mathrm{~min}, 9.54 \mathrm{~mL}$ of ethyl chloroformate ( $0.099 \mathrm{~mol}, 2$ equivalents) and $13.9 \mathrm{~mL}$ of triethylamine $\left(0.099 \mathrm{~mol}, 2\right.$ equivalents) were added and stirred at $-78{ }^{\circ} \mathrm{C}$ for $1 \mathrm{~h}$. After 
adding $23.25 \mathrm{~g}$ of (3-aminopropyl)triethoxysilane ( $0.099 \mathrm{~mol}, 2$ equivalents), the reaction mixture was stirred at $0{ }^{\circ} \mathrm{C}$ for $24 \mathrm{~h}$. At the end of that period, the reaction mixture was filtered at room temperature. After the filtrate was concentrated under reduced pressure, hexane was added. The precipitate was collected and recrystallized from THF/hexane. The precipitates were washed with diethyl ether and dried under vacuum to obtain a pure product (difunctional initiator).

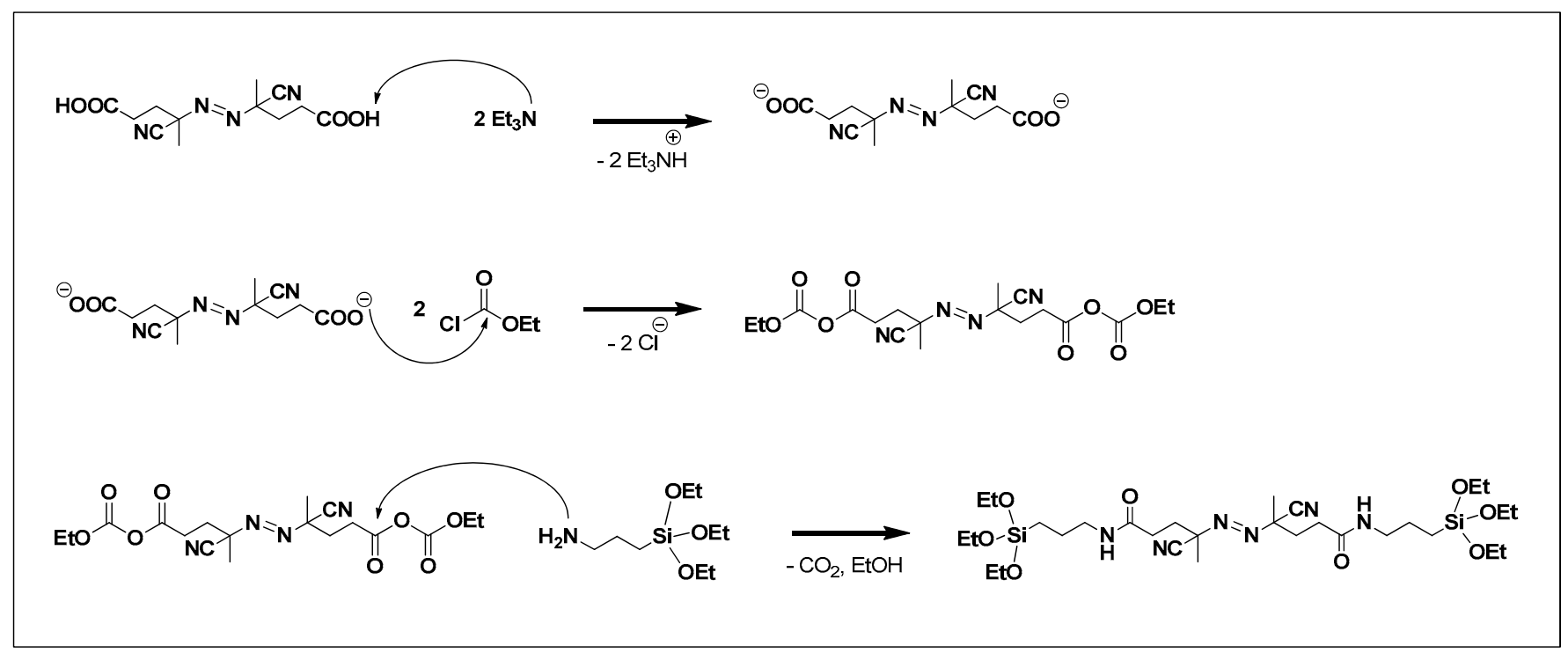

Scheme 1. Synthesis of the difunctional initiator.

\subsection{Synthesis and Functionalization of Liquid Butadiene Rubbers}

\subsubsection{Anionic Polymerization}

Non-functionalized liquid BR (NF-LqBR), one-chain end-functionalized liquid BR (OFLqBR), or center-functionalized liquid BR (CF-LqBR) were synthesized by anionic polymerization at $50{ }^{\circ} \mathrm{C}$ in a stainless-steel reactor $(2 \mathrm{~L})$ purged with nitrogen. The polymerization formulations are shown in Table 1 . The amount of $n$-butyllithium was adjusted to synthesize them with similar molecular weights, and a 6 molar ratio of anisole to $n$-butyllithium was introduced to maintain the a low vinyl content [21]. Subsequently, 1,3-butadiene was introduced into the reactor under nitrogen pressure. Polymerization of all LqBRs, except for DF-LqBR, was carried out under the same reaction conditions. After $40 \mathrm{~min}$, the reaction was terminated using $n$-octyl alcohol (1.2 molar excess to the initiator) (Scheme 2$)$. The polymerization of OF-LqBR was terminated by adding CPTES to synthesize a structure in which the terminal ends of the BR chain were modified (Scheme 3) [25-28]. In contrast, the polymerization of CF-LqBR was terminated by adding tetraethyl orthosilicate (TEOS, 0.5 molar ratio) to synthesize a structure in which two BR chains were coupled. (Scheme 4) [22,25]. Finally, LqBRs were obtained by evaporating cyclohexane in LqBR solutions using a vacuum evaporator. 


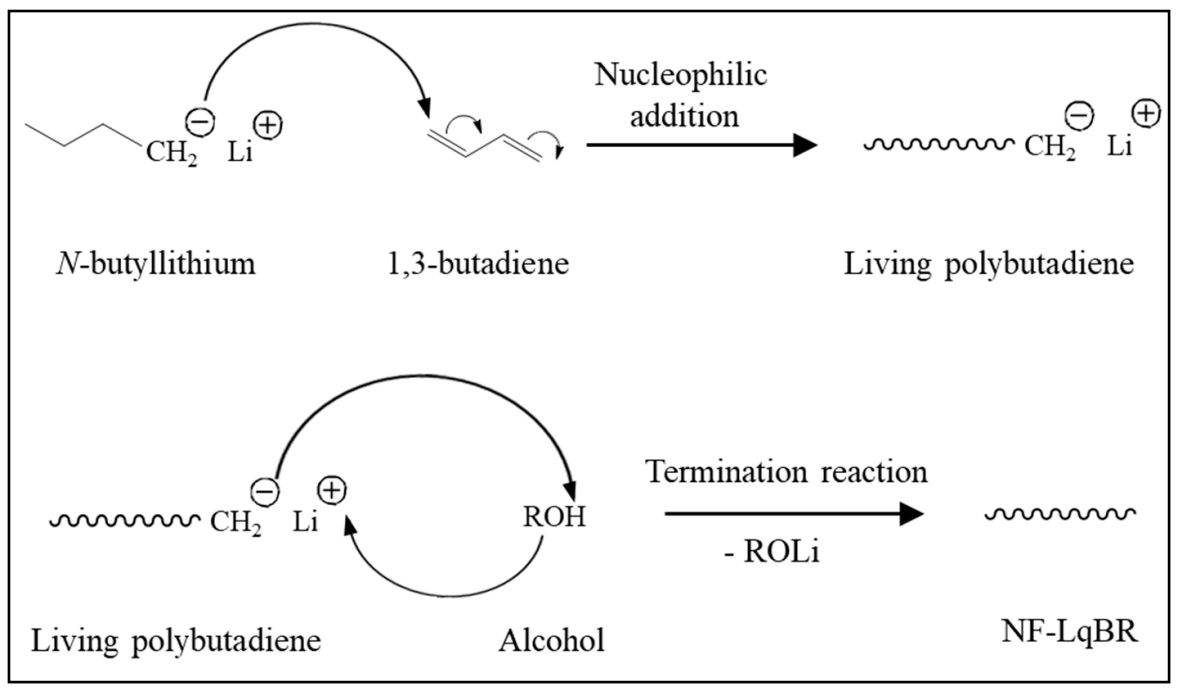

Scheme 2. Polymerization of non-functionalized liquid butadiene rubber (NF-LqBR).

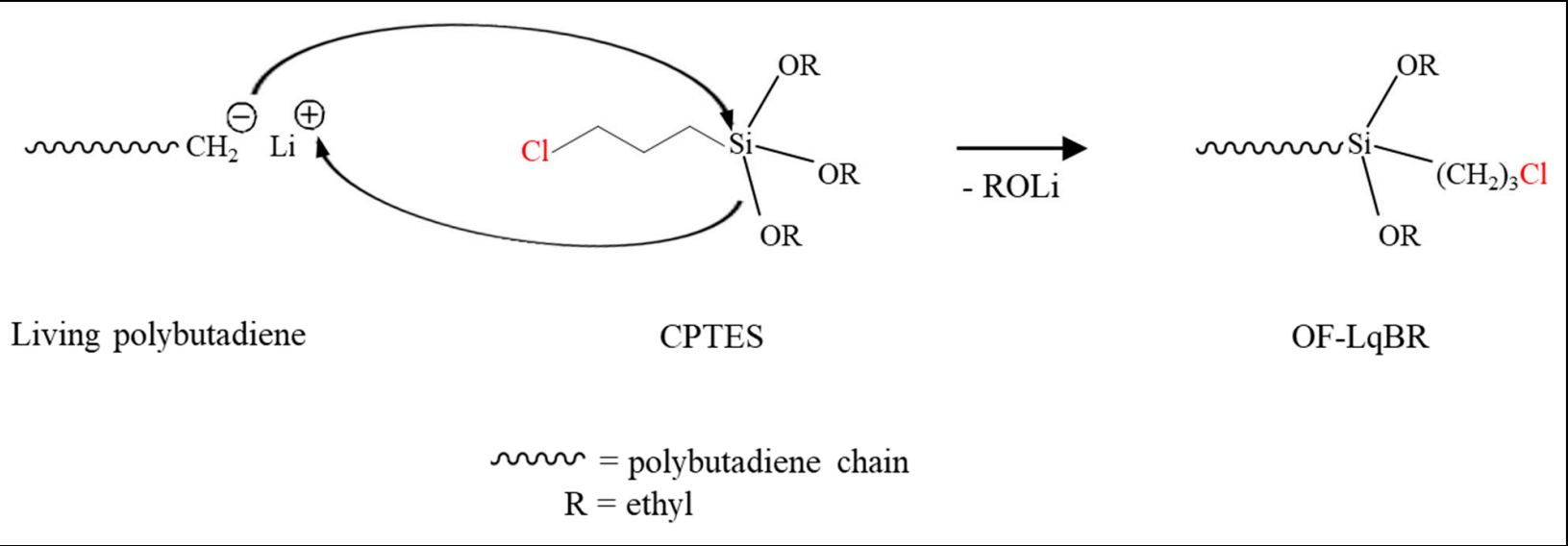

Scheme 3. Polymerization of one-chain end-functionalized liquid butadiene rubber (OF-LqBR).

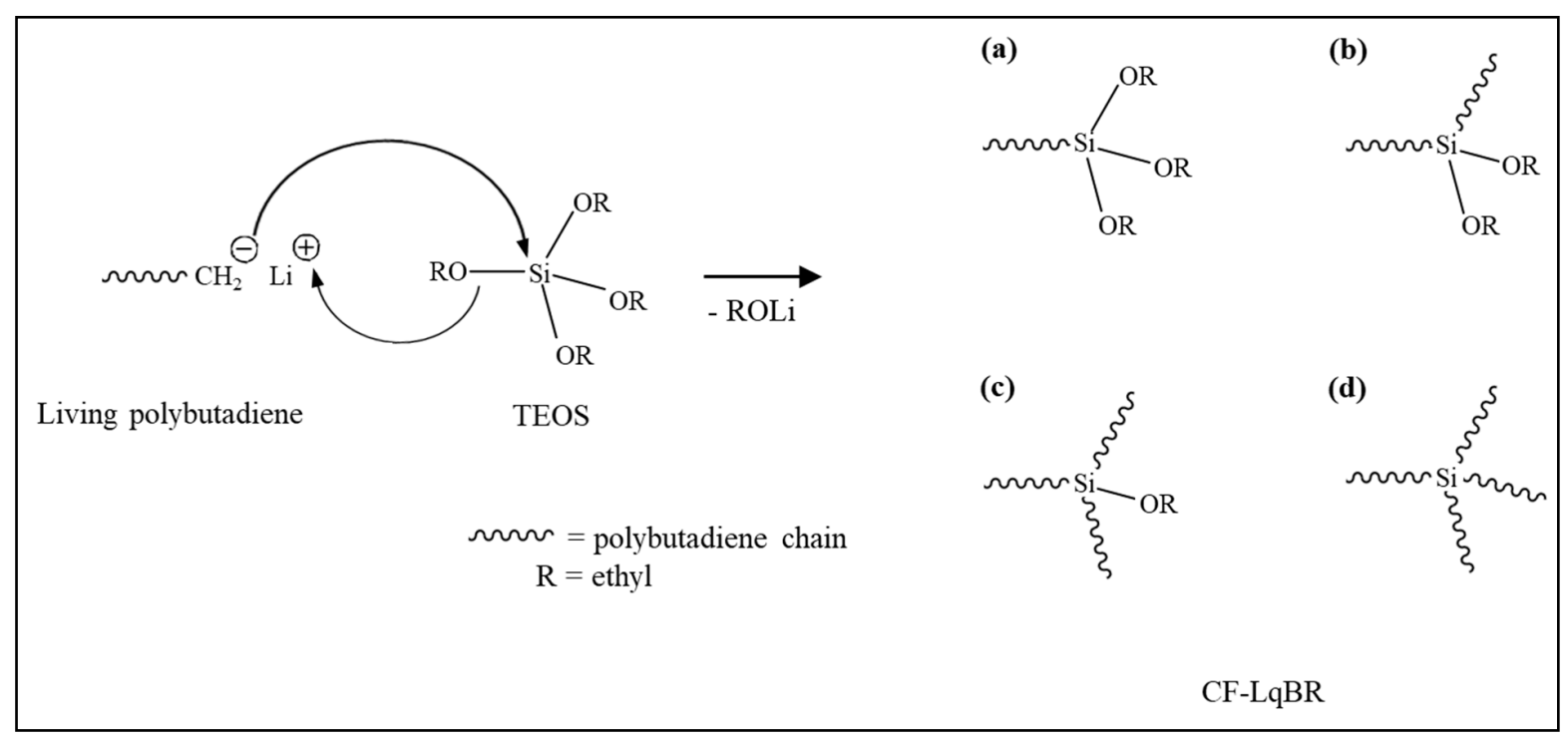

Scheme 4. Polymerization of center-functionalized liquid butadiene rubber (CF-LqBR); (a) BRSi(OR) $)_{3},(\mathbf{b}) \mathrm{BR}_{2} \mathrm{Si}(\mathrm{OR})_{2},(\mathbf{c})$ $\mathrm{BR}_{3} \mathrm{Si}(\mathrm{OR})$, and (d) $\mathrm{BR}_{4} \mathrm{Si}$. 
Table 1. Formulation for liquid butadiene rubber (LqBR) polymerization.

\begin{tabular}{ccccc}
\hline & NF-LqBR & OF-LqBR & CF-LqBR & DF-LqBR \\
\hline Butadiene (g) & 100 & 70 & 70 & 83.3 \\
Cyclohexane (g) & 500 & 400 & 400 & - \\
THF (g) & - & - & - & 416 \\
n-Butyllithium (mmol) & 3.9 & 2.8 & 5.7 & - \\
DF initiator (g) & - & - & - & 0.529 \\
Anisole (mmol) & 11.9 & 8.4 & 16.3 & - \\
CPTES (mmol) & - & 3.0 & - & - \\
TEOS (mmol) & - & - & 2.8 & - \\
n-octyl alcohol (mmol) & 4.34 & - & - & - \\
\hline
\end{tabular}

\subsubsection{Radical Polymerization}

The polymerization of 1,3-butadiene was performed in a high-pressure stainless-steel reactor $(1 \mathrm{~L})$ with a stirrer. First, the reactor was charged with $0.529 \mathrm{~g}$ of silane azo initiator and $416 \mathrm{~g}$ of THF, and purged with nitrogen gas. Next, $83.3 \mathrm{~g}$ 1,3-butadiene (measured in a small chamber) was injected into the reactor under a nitrogen pressure of 4 bar. The polymerization was carried out for $48 \mathrm{~h}$ at a temperature of $70^{\circ} \mathrm{C}$. After the reaction, the reaction mixture was cooled, and the remaining butadiene was vented from the reactor. THF was removed using rotary evaporation to concentrate the polymer solution. To remove the residual initiator, the solution was poured into ethanol to precipitate the polymers. Finally, the polymers were collected by centrifugation.

The propagating polymer chains can terminate in three ways: coupling, disproportionation, and chain transfer. If there is no chain transfer agent, the polymer chains terminate by coupling and disproportionation. In the case of butadiene, it has been reported that termination occurs by coupling $[29,30]$. Therefore, we synthesized telechelic polybutadiene with triethoxysilane terminal groups using a free radical azo initiator containing triethoxysilyl groups (Scheme 5).

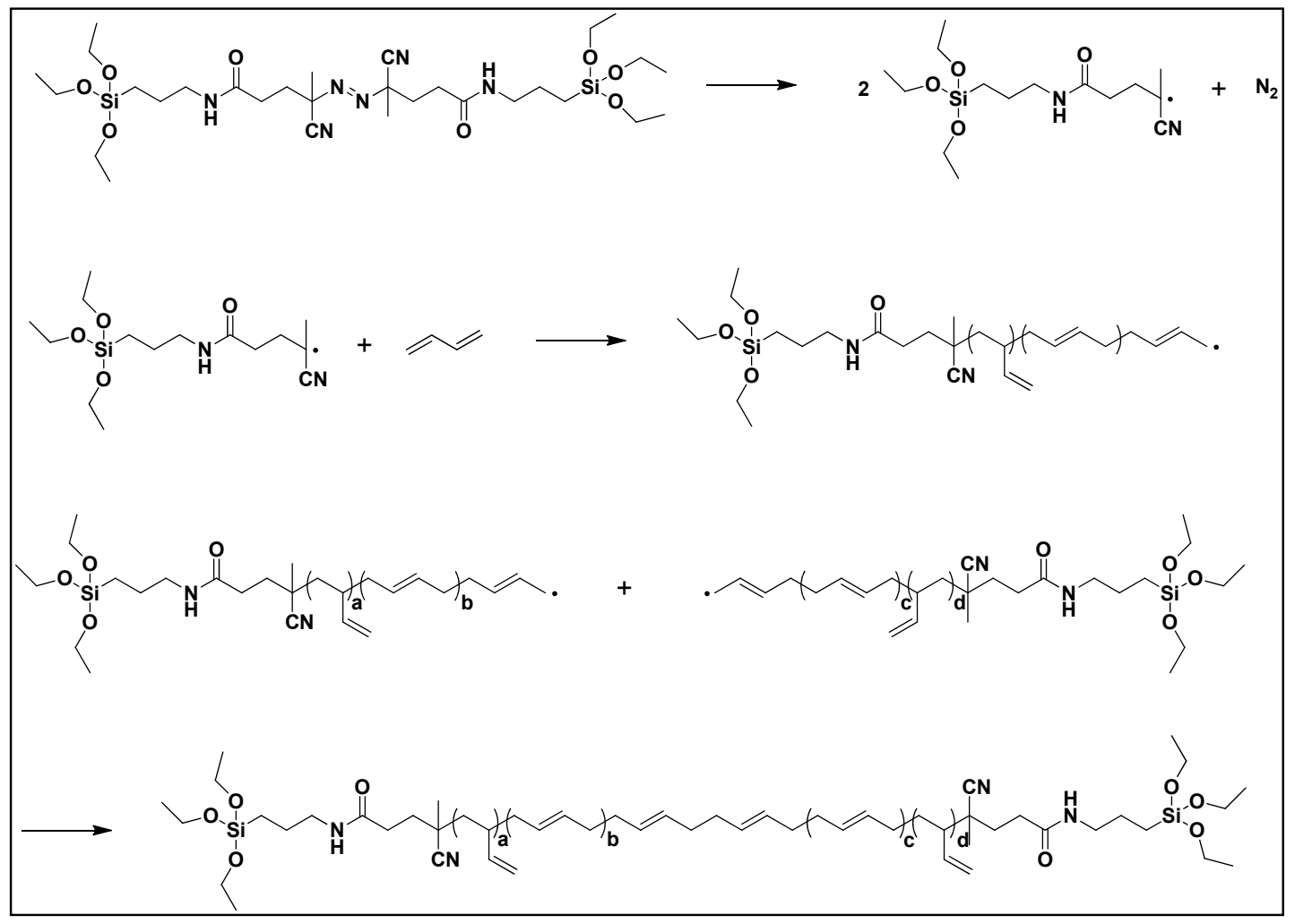

Scheme 5. Polymerization of di-functionalized liquid butadiene rubber (DF-LqBR). 
The macrostructure and microstructure of all LqBRs were analyzed by GPC and ${ }^{1} \mathrm{H}$ NMR.

\subsection{Preparation of Rubber/Silica Compounds and Vulcanizates}

The compound was prepared using an internal mixer (300 cc, Mirae Scientific Instruments Inc., Gwangju, Korea) based on the formulations listed in Table 2. The fill factor was set to $70 \%$ of the mixer capacity. The input unit was parts per hundred rubber (phr), and the formulations were added based on the rubber content. A total of $10 \mathrm{phr}$ of TDAE oil was replaced by adding LqBRs in all cases. The mixing procedures are shown in Table 3. The initial temperatures of each stage were $100{ }^{\circ} \mathrm{C}$ and $50{ }^{\circ} \mathrm{C}$, respectively, and the dump temperatures were controlled at $150-155^{\circ} \mathrm{C}$ and $80-90{ }^{\circ} \mathrm{C}$, respectively. After mixing at each stage, the compound was sheeted using a two-roll mill. After confirming the optimal vulcanization time at $160^{\circ} \mathrm{C}$ using an MDR, vulcanizates were prepared by pressing the prepared compounds in a hydraulic press at $160^{\circ} \mathrm{C}$ for the optimal vulcanization time.

Table 2. Formulation of the rubber/silica compounds using processing aids (unit: parts per hundred rubber, phr).

\begin{tabular}{cccccc}
\hline Sample Code & TDAE & NF-LqBR & OF-LqBR & CF-LqBR & DF-LqBR \\
\hline SSBR & 80 & 80 & 80 & 80 & 80 \\
BR & 20 & 20 & 20 & 20 & 20 \\
Silica & 120 & 120 & 120 & 120 & 120 \\
X50S & 20 & 20 & 20 & 20 & 20 \\
TDAE oil & 40 & 30 & 30 & 30 & 30 \\
LqBRs & 0 & 10 & 10 & 10 & 10 \\
DPG & 2 & 2 & 2 & 2 & 2 \\
ZnO & 3 & 3 & 3 & 3 & 3 \\
Stearic acid & 1 & 1 & 1 & 1 & 1 \\
6PPD & 2 & 2 & 2 & 2 & 2 \\
\hline Sulfur & 1.3 & 1.3 & 1.3 & 1.3 & 1.3 \\
CBS & 1.6 & 1.6 & 1.6 & 1.6 & 1.6 \\
\hline
\end{tabular}

Table 3. Mixing procedures.

\begin{tabular}{|c|c|c|}
\hline & Time, min:s & Action \\
\hline \multirow{10}{*}{ First stage } & $0: 00-0: 40$ & Add rubber (Initial temperature: $100^{\circ} \mathrm{C}$ ) \\
\hline & $0: 40-1: 20$ & Mixing \\
\hline & $1: 20-2: 20$ & $\begin{array}{c}\text { Add silica } 1 / 2+\text { X50S } 1 / 2+\text { DPG } 1 / 2 \\
+ \text { oil } 1 / 2+\operatorname{LgBR} 1 / 2\end{array}$ \\
\hline & $2: 20-3: 20$ & Mixing \\
\hline & $3: 20-4: 20$ & $\begin{array}{c}\text { Add silica } 1 / 2+\text { X50S } 1 / 2+\text { DPG } 1 / 2 \\
+ \text { oil } 1 / 2+\text { LqBR } 1 / 2\end{array}$ \\
\hline & $4: 20-5: 20$ & Mixing \\
\hline & $5: 20-5: 40$ & Add $\mathrm{ZnO}, \mathrm{St} / \mathrm{A}, 6 \mathrm{PPD}$ \\
\hline & $5: 40-8: 00$ & Mixing \\
\hline & $8: 00-9: 00$ & Ram up \\
\hline & 9:00-11:40 & $\begin{array}{l}\text { Additional mixing and dump } \\
\text { (Dump temperature: } 150-155^{\circ} \mathrm{C} \text { ) }\end{array}$ \\
\hline \multirow{4}{*}{ Second stage } & 0:00-0:40 & $\begin{array}{l}\text { Add a master batch from the first stage } \\
\text { (Initial temperature: } 50^{\circ} \mathrm{C} \text { ) }\end{array}$ \\
\hline & 0:40-1:00 & Mixing \\
\hline & $1: 00-1: 20$ & Add curatives \\
\hline & $1: 20-3: 00$ & $\begin{array}{l}\text { Mixing and dump } \\
\text { (Dump temperature: } 80-90^{\circ} \mathrm{C} \text { ) }\end{array}$ \\
\hline
\end{tabular}




\section{Results and Discussion}

\subsection{Synthesis of the Difunctional Initiator}

Figure 1 shows the results of ${ }^{1} \mathrm{H}$ NMR analysis of the difunctional initiator. In the difunctional initiator structure, the silyl ethoxy group $1.23\left(\mathrm{t}, 18 \mathrm{H}, \mathrm{SiO}-\mathrm{CH}_{2}-\mathrm{CH}_{3}\right), 3.84(\mathrm{q}$, $\left.12 \mathrm{H}, \mathrm{SiO}-\mathrm{CH}_{2}-\right)$, the methylene groups $3.52\left(\mathrm{~m}, 4 \mathrm{H}, \mathrm{NH}-\mathrm{CH}_{2}\right)$ next to nitrogen of amide group, $0.64\left(\mathrm{t}, 4 \mathrm{H}, \mathrm{Si}-\mathrm{CH}_{2}-\right), 1.62\left(\mathrm{q}, 4 \mathrm{H}, \mathrm{Si}-\mathrm{CH}_{2}-\mathrm{CH}_{2}\right)$ in silyl group, methylene groups group 2.16-2.52 (m, 8H, CO-CH $\left.-\mathrm{CH}_{2}, \mathrm{CO}-\mathrm{CH}_{2}\right)$, methyl peak of quaternary carbon 1.70 (s, $\left.6 \mathrm{H}, \mathrm{C}-\mathrm{CH}_{3}\right)$, and amide group $6.10(\mathrm{~s}, 1 \mathrm{H}, \mathrm{NH})$ showed those ${ }^{1} \mathrm{H}$ NMR resonance peaks.

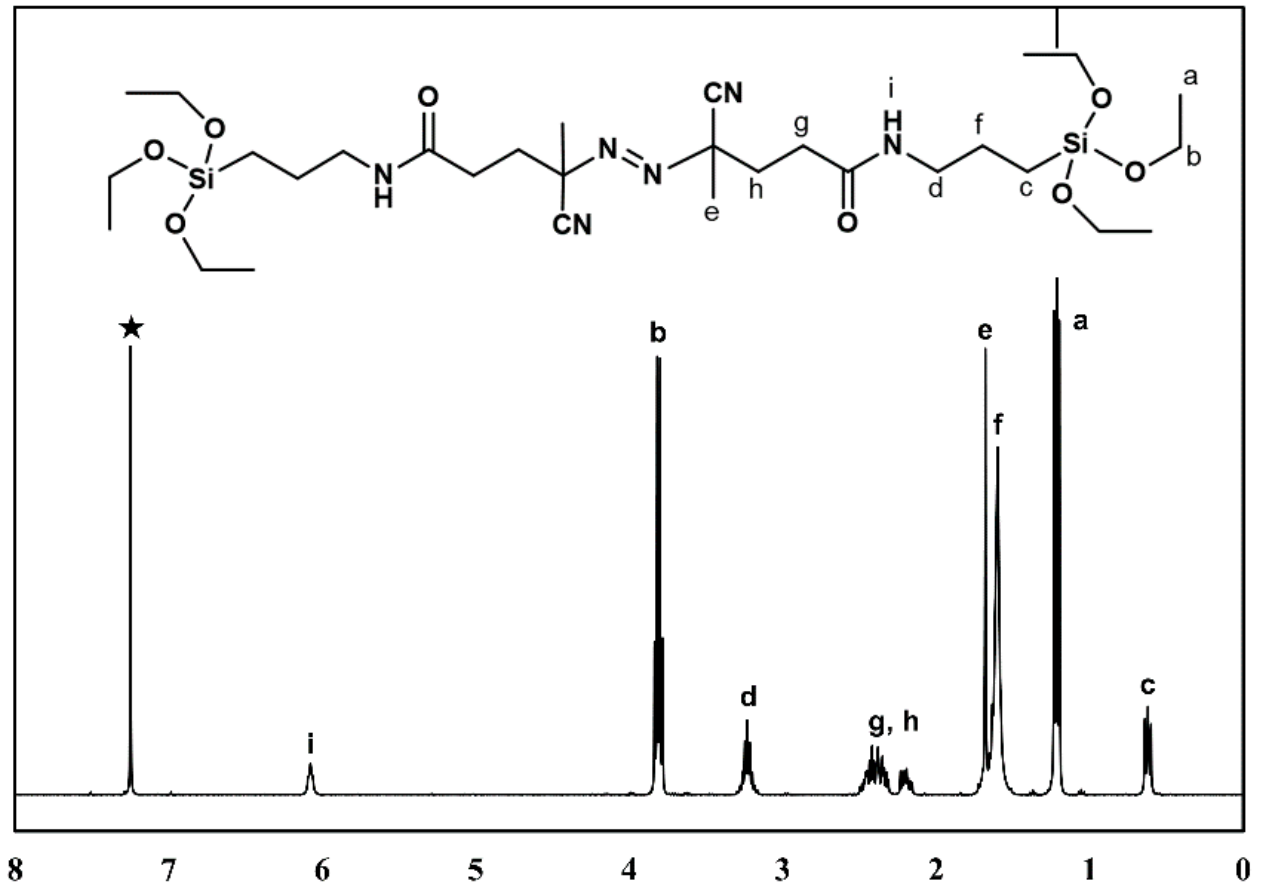

Figure 1. ${ }^{1} \mathrm{H} \mathrm{NMR}$ spectra of the difunctional initiator ( $\star \mathrm{CDCl}_{3}$ solvent).

Chemical shifts $(\delta)$ are reported with an internal standard, tetramethylsilane, and the the ${ }^{1} \mathrm{H}$ NMR peaks are shown below: ${ }^{1} \mathrm{H}$ NMR $\left(\mathrm{CDCl}_{3}\right): \delta \mathrm{ppm} 0.64\left(\mathrm{t}, 4 \mathrm{H}, \mathrm{Si}-\mathrm{CH}_{2}-\right), 1.23$ $\left(\mathrm{t}, 18 \mathrm{H}, \mathrm{SiO}-\mathrm{CH}_{2}-\mathrm{CH}_{3}\right), 1.62\left(\mathrm{q}, 4 \mathrm{H}, \mathrm{Si}-\mathrm{CH}_{2}-\mathrm{CH}_{2}\right), 1.70\left(\mathrm{~s}, 6 \mathrm{H}, \mathrm{C}-\mathrm{CH}_{3}\right), 2.16-2.52(\mathrm{~m}, 8 \mathrm{H}$, $\left.\mathrm{CO}-\mathrm{CH}_{2}-\mathrm{CH}_{2}, \mathrm{CO}-\mathrm{CH}_{2}\right), 3.52\left(\mathrm{~m}, 4 \mathrm{H}, \mathrm{NH}-\mathrm{CH}_{2}\right), 3.84\left(\mathrm{q}, 12 \mathrm{H}, \mathrm{SiO}-\mathrm{CH}_{2}-\right)$.

\subsection{Synthesis of $L q B R s$}

Figures 2 and 3, and Table 4 show the results of GPC and ${ }^{1} \mathrm{H}$ NMR of the polymerized LqBRs. Kim et al., reported that most LqBRs can be crosslinked to the base polymer by sulfur when the molecular weight of the LqBR is $25,000 \mathrm{~g} / \mathrm{mol}$ or higher [19]. In addition, Salort et al., reported that low-molecular-weight di-functionalized LqBRs can be crosslinked to the base polymer by sulfur through higher molecular-weight structure formation by self-condensation [2]. Both sets of study results clearly show that co-vulcanization with the base polymer is an important factor in determining the molecular weight of LqBRs. Based on the GPC results, NF-LqBR, OF-LqBR, and CF-LqBR synthesized by anionic polymerization had molecular weights ranging from 24,700 to $26,600 \mathrm{~g} / \mathrm{mol}$ and a narrow molecular weight distribution (1.08-1.14). DF-LqBR synthesized by radical polymerization had a molecular weight of $7400 \mathrm{~g} / \mathrm{mol}$ and a relatively broad molecular weight distribution (1.84). In the NMR spectra, resonance peaks appear at 5.37-5.50 ppm of the structure by 1,4-addition and 5.50-5.60 and 4.79-4.99 ppm of the structure (vinyl group) by 1,2-addition. The vinyl contents (anionic polymerization; $8-10 \mathrm{wt} \%$, radical polymerization; $19 \mathrm{wt} \%$ ) of LqBRs were calculated using their integration ratios [25]. ${ }^{1} \mathrm{H}$ chemical shifts of ethoxy groups on the alkoxysilyl group appear at $1.19-1.26 \mathrm{ppm}$ as a triplet $\left(\mathrm{SiO}-\mathrm{CH}_{2}-\mathrm{CH}_{3}\right)$ and at 
3.75-3.85 ppm as a quartet ( $\mathrm{SiO}-\mathrm{CH}_{2}-$ ) [31]. The chloropropyl group of OF-LqBR showed

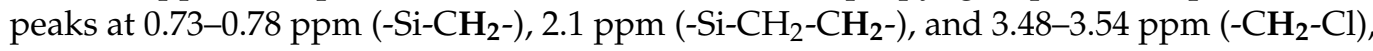
respectively $[22,25]$. The coupling number $(\mathrm{CN})$, which represents the number of coupled polybutadiene chains of CF-LqBR, was calculated as the ratio of the number-average molecular weight $\left(\mathrm{M}_{\mathrm{n}}\right)$ before and after the coupling reaction [32]:

$$
\text { Coupling number }(\mathrm{CN})=\frac{\text { Number average molecular weight after coupling }}{\text { Number average molecular weight before coupling }}
$$

Table 4. Characteristics of LqBRs.

\begin{tabular}{ccccc}
\hline & NF-LqBR & OF-LqBR & CF-LqBR & DF-LqBR \\
\hline Aliquot sample ${ }^{\mathrm{a}} \mathrm{M}_{\mathrm{n}}(\mathrm{g} / \mathrm{mol})$ & - & 25,300 & 13,000 & - \\
Final sample $\mathrm{M}_{\mathrm{n}}(\mathrm{g} / \mathrm{mol})$ & 25,500 & 26,600 & 24,700 & 7400 \\
Polydispersity index $(\mathrm{PDI})$ & 1.08 & 1.12 & 1.14 & 1.84 \\
Vinyl content $(\%$ in $\mathrm{BD})$ & 10 & 8 & 10 & 19 \\
$\mathrm{~T}_{\mathrm{g}}\left({ }^{\circ} \mathrm{C}\right)$ & -95 & -95 & -94 & -83 \\
Coupling number $(\mathrm{CN})$ & - & - & 1.9 & - \\
Functionality (Si/chain) & - & 0.98 & 1.07 & 2.22 \\
\hline
\end{tabular}

a Aliquot sample; LqBR sample before addition to TEOS.

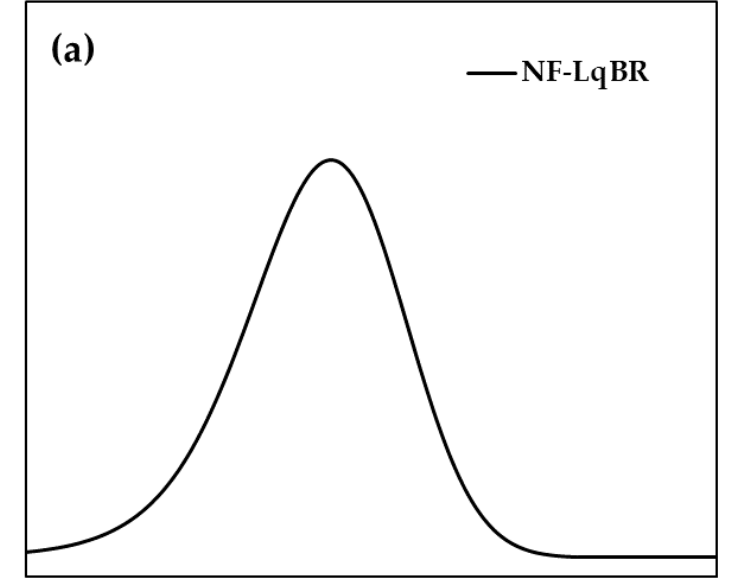

10,000

Molecular weight $(\mathrm{g} / \mathrm{mol})$

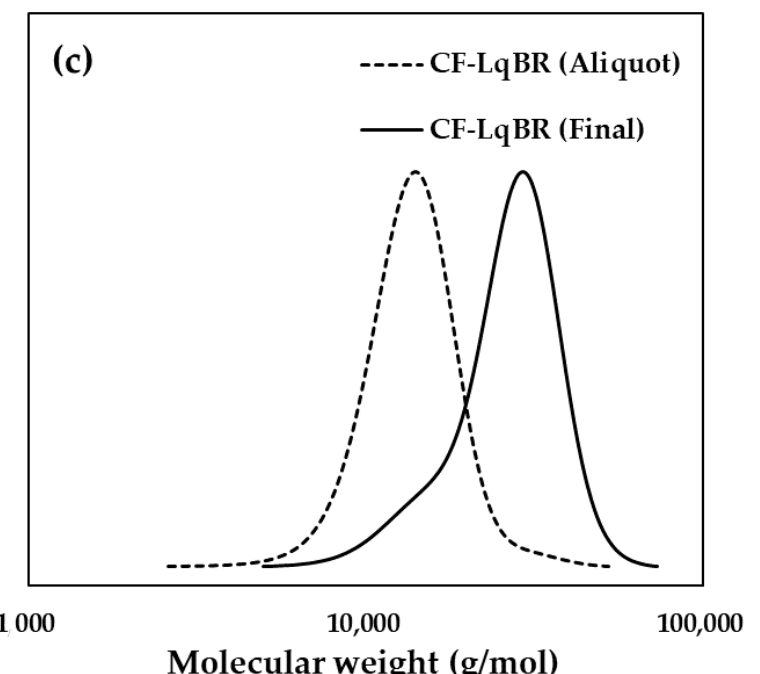

Molecular weight $(\mathrm{g} / \mathrm{mol})$

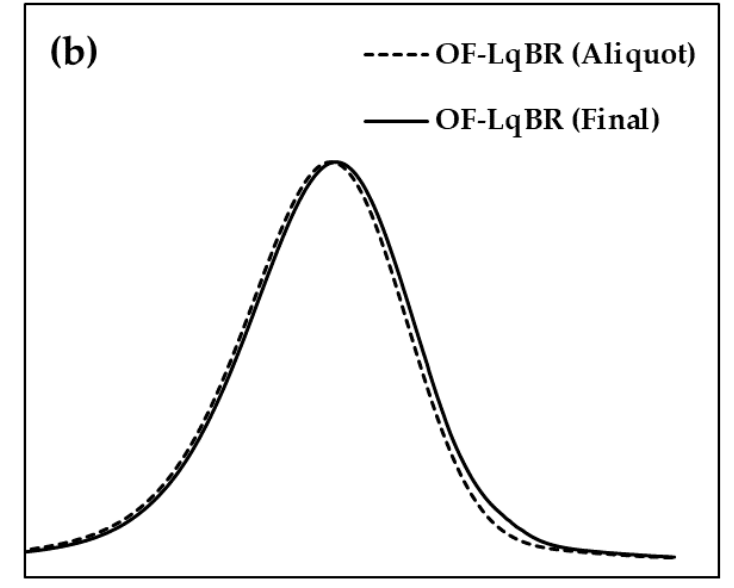

10,000

(d)

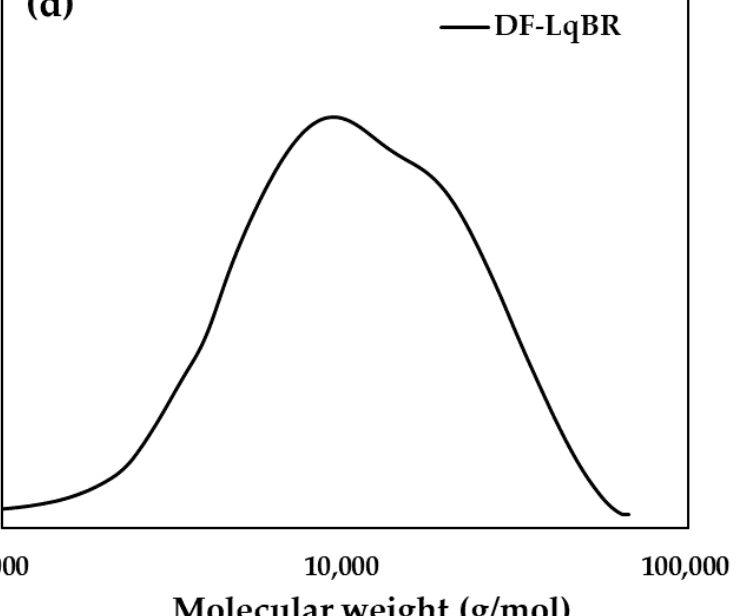

1000
Molecular weight $(\mathrm{g} / \mathrm{mol})$

-DF-LqBR

100,000

Molecular weight $(\mathrm{g} / \mathrm{mol})$

Figure 2. Gel permeation chromatography (GPC); (a) NF-LqBR, (b) OF-LqBR, (c) CF-LqBR, and (d) DF-LqBR. 

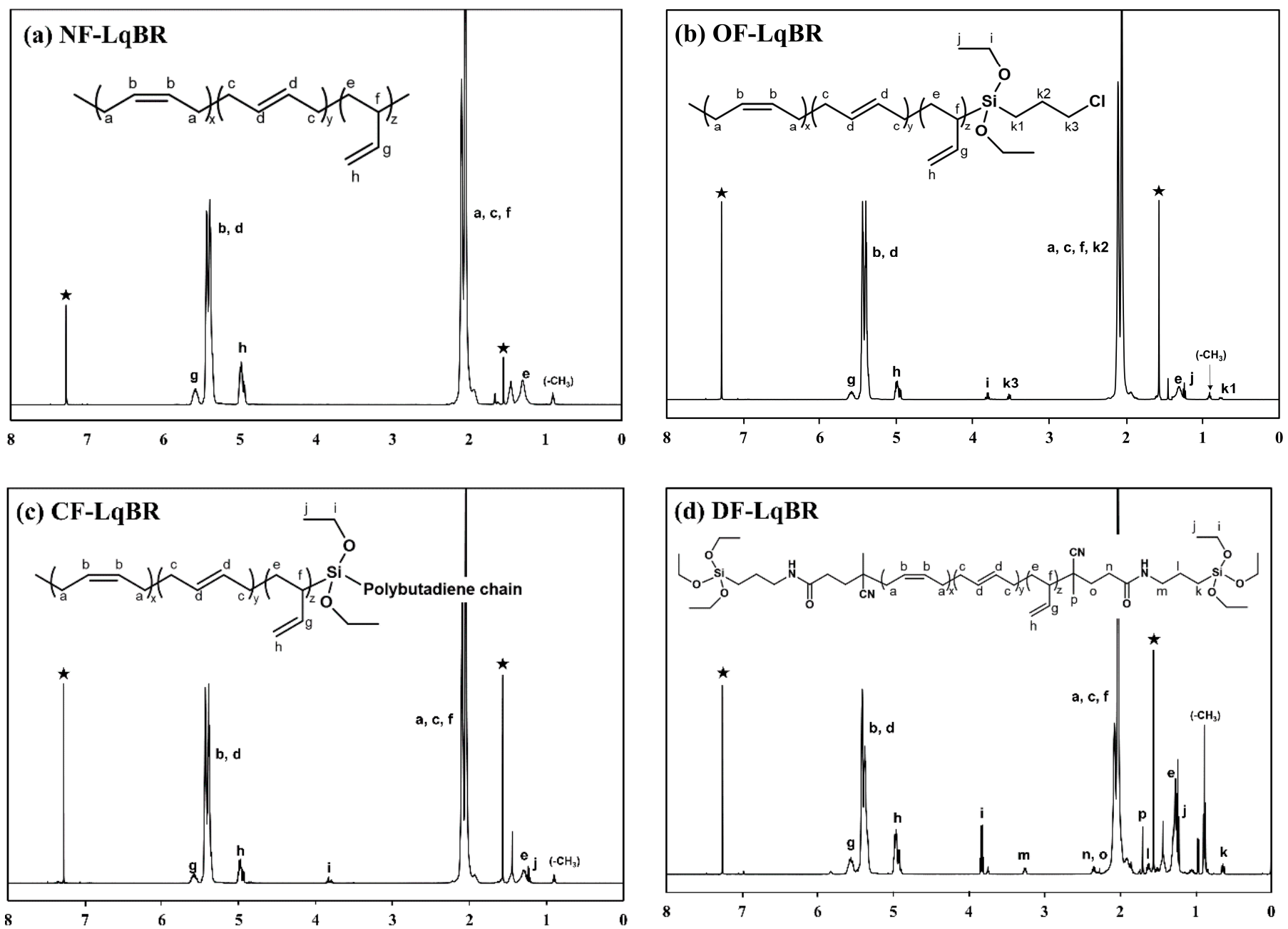

Figure 3. ${ }^{1} \mathrm{H}$ NMR spectra; (a) NF-LqBR, (b) OF-LqBR, (c) CF-LqBR, and (d) DF-LqBR $\star$ Resonance peak of CDCl 3 at 1.57 and $7.26 \mathrm{ppm}$; due to solvent impurities and residual $\mathrm{H}$.

The CN of CF-LqBR was 1.9, which indicates that the coupling reaction of the two polybutadiene chains (Scheme $4 \mathrm{~b}$ ) was dominant.

In the ${ }^{1} \mathrm{H} \mathrm{NMR}$ spectra, the area of the resonance peak for each $\mathrm{H}$ atom is proportional to the number of $\mathrm{H}$ atoms. According to this principle, the functionality, which is the ratio of the chain that contains the ethoxy-silyl group to the entire LqBR chain, was calculated as the integration of protons on the vinyl groups to the integration of protons on the alkoxylsilyl groups [33]:

$$
\frac{S_{\text {Vinyl-H }}}{S_{\text {Alkoxysilane }-H}}=\frac{2 \times\left(R_{\text {Vinyl }}\right) \times\left(M_{n} / M_{B}\right)}{n_{\text {Alkoxysilane }} \times F}
$$

where $S_{\text {vinyl-H}}$ and $S_{\text {Alkoxysilane-H }}$ are the peak areas of $\mathrm{H}$ atoms of vinyl and alkoxysilane, respectively; $R_{V i n y l}$ is the vinyl content; $M_{n}$ is the number-average molecular weight of LqBR; $M_{B}$ is the molecular weight of butadiene, $n_{\text {alkoxysilane }}$ is the number of $\mathrm{H}$ atoms of alkoxysilane, i.e., -Si- $\left(\mathrm{OCH}_{2} \mathrm{CH}_{3}\right)_{3} ;$ " 4 ", " 4 ", and "6" are, respectively, for OF-LqBR, CFLqBR, and DF-LqBR; and $F$ is the functionality (Si/chain). For example, " 2 " indicates the two functionalized ends of macromolecular chains.

\subsection{Manufacture of Rubber/Silica Compounds}

The compounds were mixed in two stages. The mixing torque of the compounds during the first step is shown in Figure 4 and Table 5. The mixing procedure of the first 
mixing stage includes the following steps (in min:s): 1 . at 0:00 rubber addition; 2 . at 1:20 addition of $50 \%$ of the silica, X50S, DPG, and TDAE or LqBR; 3 . at 3:20 addition of the remaining 50\% of the silica, X50S, DPG, and TDAE or LqBR; 4 . at 5:20 addition of the zinc oxide, stearic acid, and 6PPD; 5 . discharge at 11:40. The starting temperature of the mixer was set at a temperature of $100{ }^{\circ} \mathrm{C}$. The targeted temperature at the end of the mixing was $150-155{ }^{\circ} \mathrm{C}$ for the compound to reach a silanization with the silane coupling agent. The second mixing step was carried out in the same mixer. The amounts of accelerators and sulfur were recalculated according to the mass of the compound after the first mixing stage.

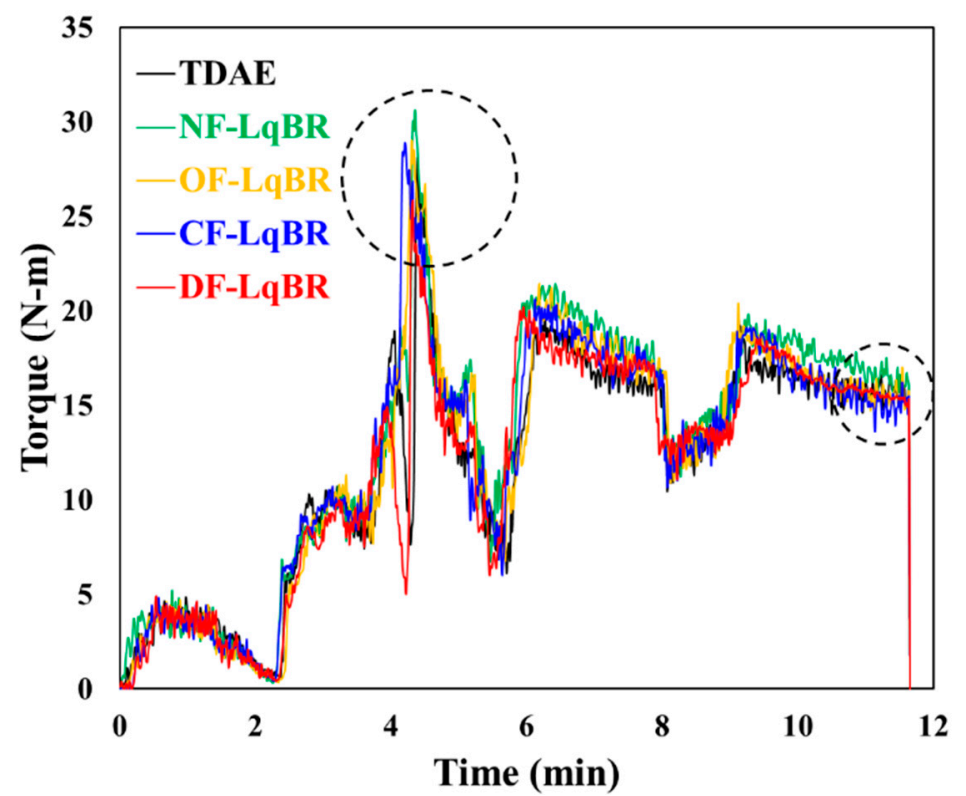

Figure 4. Mixing torque of the compounds during the first stage.

Table 5. Peak torque of the compounds during the first stage mixing.

\begin{tabular}{cccccc}
\hline Compound & TDAE & NF-LqBR & OF-LqBR & CF-LqBR & DF-LqBR \\
\hline Peak torque $(\mathrm{N}-\mathrm{m})$ & 28.1 & 30.6 & 29 & 28.9 & 25.8 \\
\hline
\end{tabular}

\subsection{Payne Effect}

The Payne effect presented in Figure 5 and Table 6 indicates the filler-filler interaction of the uncured compound. A decrease in the storage modulus $\left(\mathrm{G}^{\prime}\right)$ with increasing strain amplitude is a result of the destruction of the filler network. The larger the $\Delta G^{\prime}$ value, the stronger the filler-filler interaction [34].

Table 6. $\Delta \mathrm{G}^{\prime}$ values of the compounds.

\begin{tabular}{cccccc}
\hline Compound & TDAE & NF-LqBR & OF-LqBR & CF-LqBR & DF-LqBR \\
\hline $\begin{array}{c}\Delta \mathrm{G}^{\prime} \\
(0.28-40.04 \%, \mathrm{MPa})\end{array}$ & 6.54 & 5.47 & 5.2 & 5.04 & 4.23 \\
\hline
\end{tabular}




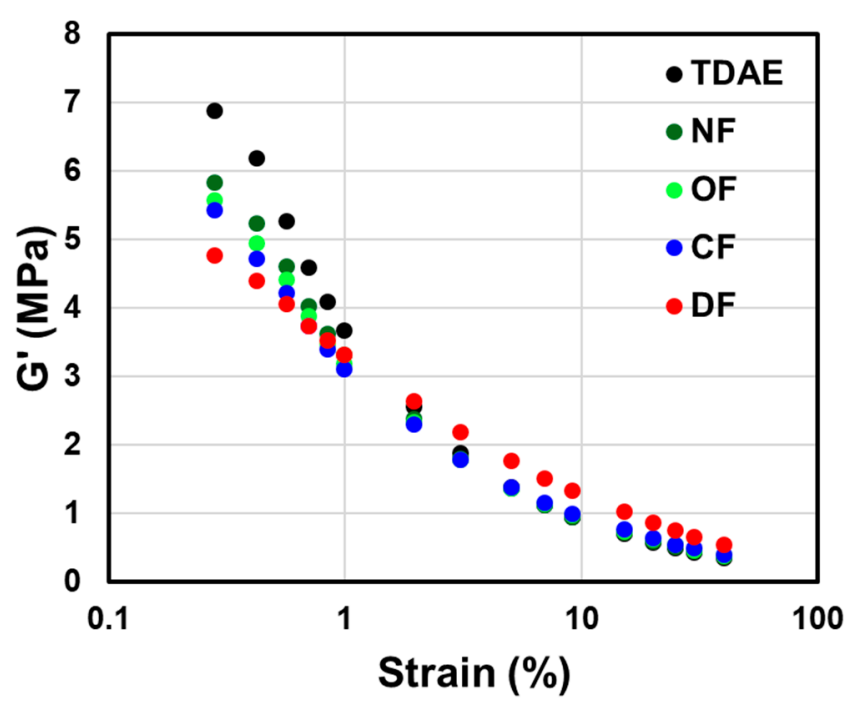

Figure 5. Storage modulus $\left(\mathrm{G}^{\prime}\right)$ of the uncured compounds according to the applied processing aids.

Sufficient viscosity and shearing force are required during the mixing process to achieve excellent silica dispersion within the compound [1,19]. Due to the fact that LqBRs, which have higher molecular weights than TDAE oils (molecular weight $<500 \mathrm{~g} / \mathrm{mol}$ ), possess higher viscosity, high peak torque values were obtained in the first stage of the mixing process, as shown in Figure 4 and Table 5. As a result, all compounds to which the LqBR was applied showed improved silica dispersion and a lower Payne effect, as compared to the compound with TDAE oils. In particular, OF-LqBR and CF-LqBR showed lower $\Delta \mathrm{G}^{\prime}(0.28-40.04 \%$, MPa) values than NF-LqBR, which has a similar molecular weight because of the improved dispersion, as the ethoxy group modifies the silica surface. In addition, DF-LqBR exhibited the lowest $\Delta \mathrm{G}^{\prime}$ value owing to its excellent hydrophobation effect for silica surface.

\subsection{Cure Characteristics and Mooney Viscosity}

The mixing process shown in Figure 4 is a method to maintain the dump temperature $\left(150-155^{\circ} \mathrm{C}\right)$ of the compound by adjusting the rotor RPM. Hence, it is not possible to compare the processability of each compound with the final torque value. Therefore, the Mooney viscosity, which is related to the processability of the compound, was measured. The Mooney viscosity results, and the cure characteristics obtained using an MDR are shown in Table 7 and Figure 6. LqBRs not only improve silica dispersion, but also show lower Mooney viscosity and minimum torque $\left(\mathrm{T}_{\mathrm{min}}\right)$ values, as compared with the TDAE compound, because chain slippage is facilitated by acting as a lubricant between the base polymer chains $[1,19]$. The compounds with OF-LqBR and CF-LqBR exhibited lower Mooney viscosity and $\mathrm{T}_{\min }$ values than NF-LqBR owing to the improved silica dispersion. In particular, because the branched CF-LqBR has a smaller hydrodynamic radius than the linear OF-LqBR, it has a lower viscosity [35], and the Mooney viscosity and $\mathrm{T}_{\min }$ values of the compound tend to decrease. In contrast, DF-LqBR, which has a low entanglement effect owing to its relatively low molecular weight, was expected to have the lowest viscosity [36-38], but rather showed similar values to that of TDAE compounds. This is because the amide and cyano groups at the chain end of DF-LqBR form strong hydrogen bonds with the amide and cyano groups of other DF-LqBR chains, which limits chain mobility and thereby increases viscosity [30]. 
Table 7. Cure characteristics and Mooney viscosity of the compounds.

\begin{tabular}{cccccc}
\hline Compound & TDAE & NF-LqBR & OF-LqBR & CF-LqBR & DF-LqBR \\
\hline $\mathrm{t}_{10}(\min : \mathrm{s})$ & $01: 19$ & $01: 01$ & $01: 00$ & $01: 00$ & $01: 14$ \\
$\mathrm{t}_{90}(\min : \mathrm{s})$ & $11: 00$ & $12: 10$ & $11: 58$ & $11: 38$ & $10: 37$ \\
$\mathrm{~T}_{\min }(\mathrm{N} \cdot \mathrm{m})$ & 0.9 & 0.77 & 0.75 & 0.74 & 0.8 \\
$\mathrm{~T}_{\max }(\mathrm{N} \cdot \mathrm{m})$ & 3.11 & 2.73 & 2.89 & 2.83 & 2.92 \\
$\triangle \mathrm{T}$ & 2.21 & 1.96 & 2.14 & 2.09 & 2.12 \\
$\left(\mathrm{~T}_{\max }-\mathrm{T}_{\min }, \mathrm{N} \cdot \mathrm{m}\right)$ & & & & & \\
Mooney viscosity $_{\left(\mathrm{ML}_{1+4} @ 100^{\circ} \mathrm{C}\right)}$ & 154 & 148 & 145 & & 151 \\
\hline
\end{tabular}

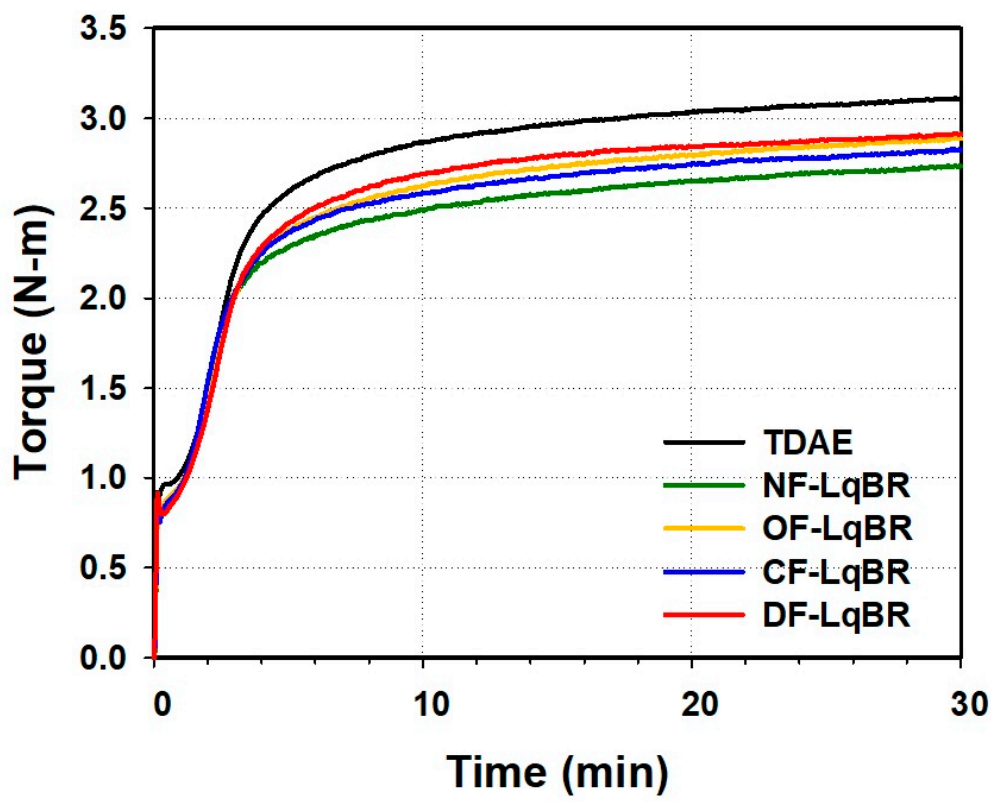

Figure 6. Cure curves of the compounds according to the applied processing aids.

In the case of silica compounds, the delta torque $\left(\Delta T, T_{\max }-T_{\min }\right)$ value in the MDR curve is affected by the filler morphology and the crosslink density [39]. In general, the $\Delta \mathrm{T}$ values of NF-LqBR compounds are lower than those of TDAE oil because NF-LqBR consumes sulfur, which is used for the crosslinking reaction between the base polymers. In contrast, functionalized-LqBRs can increase filler-rubber interactions by not only fixing functional groups on the silica surface, but also forming chemical bonds with the base polymers through a crosslinking reaction with the base polymer. Furthermore, DF-LqBR forms a network structure by self-condensation between ethoxy groups, which limits chain mobility [5]. For this reason, it is considered that the compounds to which functionalizedLqBRs were applied showed higher $\Delta \mathrm{T}$ values than NF-LqBR compounds, even though the silica dispersion was excellent. Therefore, their crosslink density values are expected to be higher than those of NF-LqBR compounds [40].

\subsection{Solvent Extraction and Crosslink Density}

Organic matter was extracted from vulcanizate specimens using two types of organic solvents, and the amount of organic matter was determined. First, oils and low-molecularweight components added during mixing were extracted using THF. Soluble free LqBRs were then extracted using $n$-hexane from the specimen obtained after extraction with THF. The total amount of organic matter extracted using the two different organic solvents is shown in Figure 7a and Table 8. 

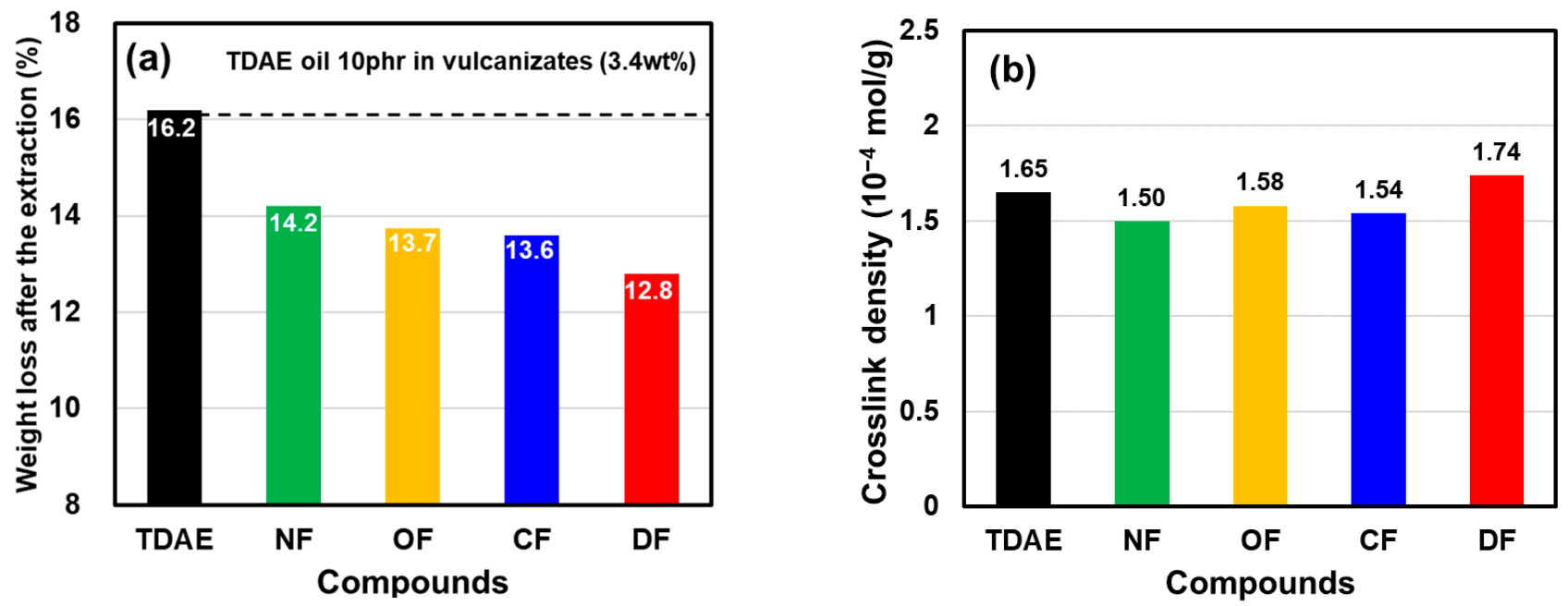

Figure 7. (a) Weight loss after extraction and (b) crosslink density of the vulcanizates.

Table 8. Weight loss of the vulcanizates after extraction and crosslink density.

\begin{tabular}{|c|c|c|c|c|c|}
\hline Compound. & TDAE & NF-LqBR & OF-LqBR & CF-LqBR & DF-LqBR \\
\hline Weight loss after the extraction (wt $\%$ ) & 16.2 & 14.2 & 13.7 & 13.6 & 12.8 \\
\hline $\begin{array}{l}\text { Weight loss after the extraction } \\
\text { in 10phr of TDAE oil and LqBRs (\%) }\end{array}$ & 100 & 41.2 & 26.5 & 23.5 & 0 \\
\hline Crosslink density $\left(10^{-4} \mathrm{~mol} / \mathrm{g}\right)$ & 1.65 & 1.50 & 1.58 & 1.54 & 1.76 \\
\hline
\end{tabular}

The proportion of $40 \mathrm{phr}$ of TDAE oils in the vulcanizate specimen was $13.6 \mathrm{wt} \%$, of which $10 \mathrm{phr}$ corresponded to $3.4 \mathrm{wt} \%$. The TDAE compound showed the highest organic matter extraction amount at $16.2 \mathrm{wt} \%$ (40 phr of TDAE oil; $13.6 \mathrm{wt} \%$ + some additives; $2.6 \mathrm{wt} \%$ ). This is because the oil can easily be extracted by organic solvents, as it does not form a chemical bond with other materials in the compound. In contrast, approximately $58.8 \%$ of NF-LqBR, which has a molecular weight of $25,500 \mathrm{~g} / \mathrm{mol}$, can be fixed in the polymer network through co-vulcanization with the base polymers during vulcanization. Therefore, a smaller extraction amount was obtained, as compared with the TDAE compounds. The extraction amount obtained from OF-LqBR and CF-LqBR was smaller than from NF-LqBR because the functional groups can be fixed on the silica surface by the silanization reaction, in addition to co-vulcanization with the base polymer (i.e., LqBR extraction amount: $41.2 \%$ versus $26.5 \%$ and $23.5 \%$ ). In particular, in the case of DF-LqBR with 2.2 functional groups per chain, the extraction amount was reduced to $10 \mathrm{phr}(3.4 \mathrm{wt} \%)$ that replaced TDAE oils (i.e., DF-LqBR extraction amount: $0 \%$ ). Therefore, it is considered that DF-LqBR was not extracted from the vulcanizate.

The crosslink densities of the vulcanizates are shown in Figure $7 \mathrm{~b}$ and Table 8. LqBR generally reduces the crosslink density of the vulcanizate because it consumes sulfur for use in the base polymer crosslinking. However, OF-LqBR and CF-LqBR formed chemical bonds between silica and rubber, resulting in higher crosslink density values than that of the NF-LqBR compound. In particular, OF-LqBR has a large entanglement effect because its molecular weight is twice that of the CF-LqBR chain before the coupling reaction [40], which is advantageous for the crosslinking reaction to form a crosslinking point with the base polymer [8]. Therefore, the crosslink density of OF-LqBR was larger than that of CFLqBR. In the case of DF-LqBR, the network structure formed through self-condensation [5] not only has swelling resistance, but also forms chemical bonds between silica and rubber, even though it has a small molecular weight of $7400 \mathrm{~g} / \mathrm{mol}$. Thus, it showed higher crosslink density values, as compared with the OF-LqBR and CF-LqBR compounds. 


\subsection{Mechanical Properties and DIN Abrasion Loss}

The mechanical properties and DIN abrasion loss measurement results are shown in Figure 8 and Table 9, respectively. It is known that the modulus at $300 \%$ elongation $\left(\mathrm{M}_{300}\right)$ in the stress-strain curves is highly correlated with the crosslink density [20]. LqBR generally acts as a lubricant between the base polymer chains to facilitate slippage and decrease the modulus owing to a decrease in the crosslink density value by consuming sulfur. However, the OF-LqBR and CF-LqBR compounds showed similar $\mathrm{M}_{300}$ values, as compared with those of the TDAE compound, even though the crosslink density was lower. This is caused not only by increased filler-rubber interactions owing to the coupling reaction of OF-LqBR and CF-LqBR, but also by increased modulus owing to the effect of chain entanglement $[19,35]$. In the case of DF-LqBR, the crosslink density increased because of the network structure formed by self-condensation, which resulted in the highest $\mathrm{M}_{300}$ value.

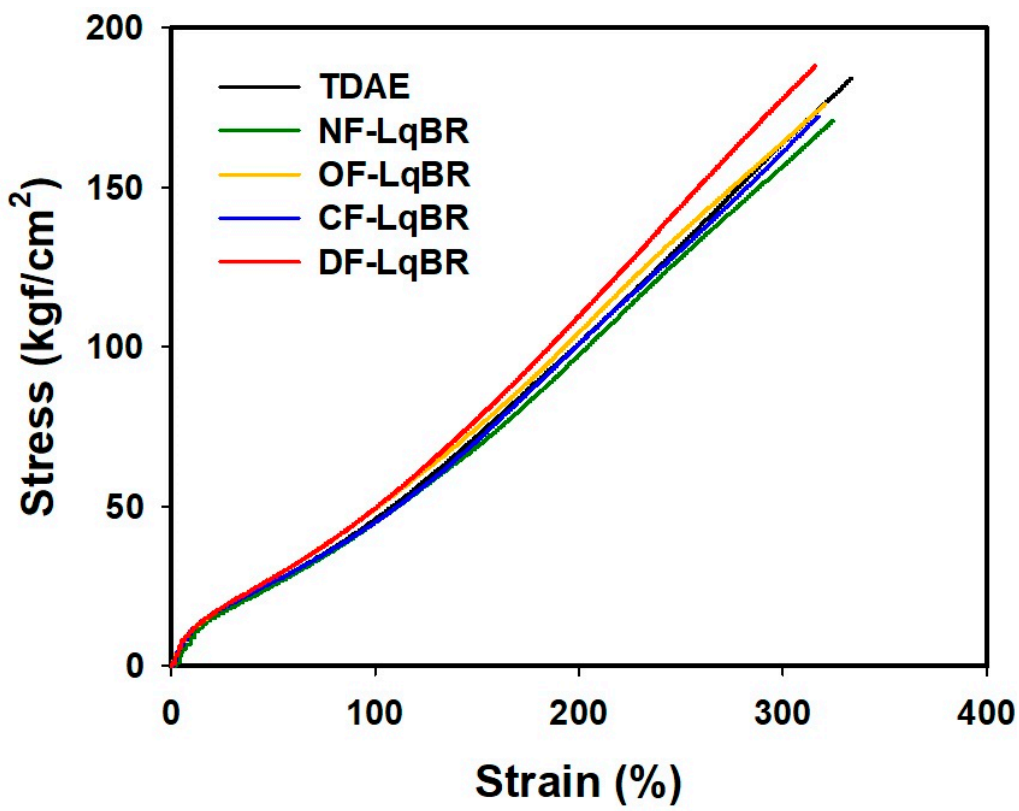

Figure 8. Stress-strain curves of the vulcanizates according to the applied processing aids.

Table 9. Mechanical properties and DIN abrasion loss of the vulcanizates.

\begin{tabular}{cccccc}
\hline Compound & TDAE & NF-LqBR & OF-LqBR & CF-LqBR & DF-LqBR \\
\hline $\mathrm{M}_{100}\left(\mathrm{kgf} / \mathrm{cm}^{2}\right)$ & 46 & 45 & 49 & 45 & 49 \\
$\mathrm{M}_{300}\left(\mathrm{kgf} / \mathrm{cm}^{2}\right)$ & 164 & 156 & 164 & 161 & 178 \\
Elongation at break $(\%)$ & 334 & 325 & 321 & 318 & 316 \\
Tensile strength $\left(\mathrm{kgf} / \mathrm{cm}^{2}\right)$ & 184 & 171 & 176 & 172 & 188 \\
DIN abrasion loss $(\mathrm{mg})$ & 121 & 102 & 99 & -43 & 100 \\
Compound $\mathrm{T}_{\mathrm{g}}\left({ }^{\circ} \mathrm{C}\right)$ & -40.0 & -43.2 & -43.5 & -43.1 & -42.3 \\
\hline
\end{tabular}

In general, it is known that abrasion resistance is significantly affected by the $T_{g}$ of the polymer and the filler-rubber interaction [41-44]. In addition, Seo et al., reported that, in silica-filled compounds, the abrasion resistance according to the macrostructure (linear-shaped SBR versus star-shaped SBR) of the polymer was better with the star-shaped SBR with advantageous silica dispersion [45]. The LqBR, which has lower $T_{g}$ than TDAE oils, showed excellent abrasion resistance in all compounds by lowering the compound $\mathrm{T}_{\mathrm{g}}$. In addition, F-LqBRs that are capable of the coupling reaction increased the filler-rubber interaction and showed improved abrasion resistance, as compared with the NF-LqBR compounds. The CF-LqBR compound exhibited superior abrasion resistance, as compared 
with the OF-LqBR compound, as the silica dispersion improved, which was confirmed in the previous Payne effect result. DF-LqBR has excellent silica dispersion and high filler-rubber interaction. However, the degree of improvement in the abrasion resistance was small, as compared to that of OF-LqBR and CF-LqBR owing to the high $\mathrm{T}_{\mathrm{g}}$ of DF-LqBR. Consequently, the $\mathrm{T}_{\mathrm{g}}$ of the LqBR, in addition to the silica dispersion improvement and the increase in the filler-rubber interaction, is considered to be the most important factor influencing the abrasion resistance of compounds to which LqBRs are applied.

\subsection{Dynamic Viscoelastic Properties}

To predict the tire performance, the viscoelastic properties of tread compounds can be measured in the laboratory with excellent correlation. Among the viscoelastic properties, the storage modulus $\left(\mathrm{G}^{\prime}\right)$ value in the low-temperature region below $-10{ }^{\circ} \mathrm{C}$ is an indicator of snow traction, and the lower the value, the better the snow traction [46,47]. This is because the tire tread can be deformed and adhered to the icy road surface more easily when the $G^{\prime}$ value is lower under low-temperature conditions [48]. The value of the loss modulus $\left(\mathrm{G}^{\prime \prime}\right)$ at $0{ }^{\circ} \mathrm{C}$, which is used as an indicator of the tire wet traction, is known to improve the wet traction performance as the value is increased. In addition, the $\mathrm{G}^{\prime \prime}$ value tends to increase with the effective filler volume fraction [49]. The value of $\tan \delta$ at $60{ }^{\circ} \mathrm{C}$ is an indicator of the rolling resistance of tires, and the lower the value, the better the fuel economy performance [50]. The main energy dissipation in the high-temperature region is due to the destruction and reformation of the filler-filler network [49]. Kitamura et al., reported that free chain ends of the polymers also contribute to hysteresis in this region [51]. Salort et al., reported that when low-molecular-weight butadiene rubber is crosslinked to the base polymers, hysteresis occurs because of dangling chain ends [8]. The results of both studies suggest that free chain ends of the polymers are also an important factor in the energy loss in the high-temperature region.

Figure 9 and Table 10 show the results of the dynamic viscoelastic properties of the compounds to which TDAE oils or LqBRs are applied. All LqBR compounds showed lower values of $\mathrm{G}^{\prime}$ at $-30{ }^{\circ} \mathrm{C}$ than the TDAE compound, regardless of the functional group position. This is because LqBRs with low $\mathrm{T}_{\mathrm{g}}$ lowered the $\mathrm{T}_{\mathrm{g}}$ of the compounds and increased the flexibility of the compounds at low temperatures.

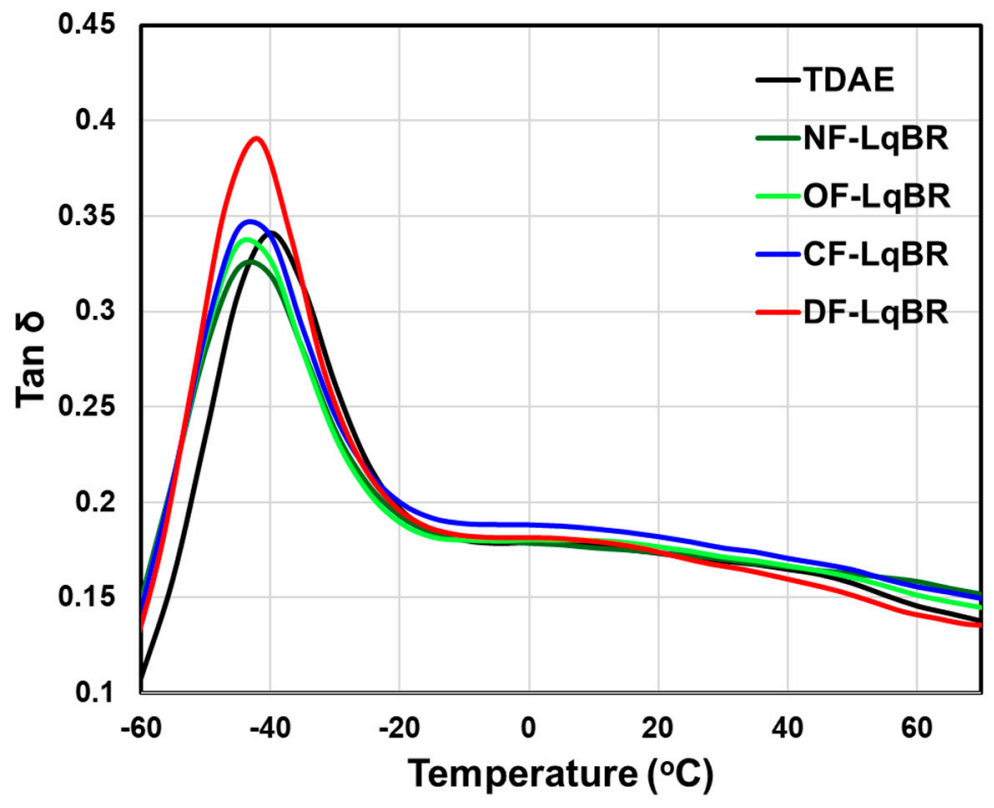

Figure 9. Tan $\delta$ curves of the vulcanizates according to the applied processing aids. 
Table 10. Viscoelastic properties of the compounds according to the applied processing aids.

\begin{tabular}{cccccc}
\hline Compound & TDAE & NF-LqBR & OF-LqBR & CF-LqBR & DF-LqBR \\
\hline $\mathrm{T}_{\mathrm{g}}\left({ }^{\circ} \mathrm{C}\right)$ & -40.0 & -43.2 & -43.5 & -43.1 & -42.3 \\
$\mathrm{G}^{\prime}$ at $-30^{\circ} \mathrm{C}(\mathrm{MPa})$ & 172 & 154 & 155 & 148 & 147 \\
$\mathrm{G}^{\prime \prime}$ at $0{ }^{\circ} \mathrm{C}(\mathrm{MPa})$ & 12.0 & 11.5 & 11.3 & 11.1 & 0.7 \\
Tan $\delta$ at $60^{\circ} \mathrm{C}$ & 0.145 & 0.158 & 0.151 & 1 & 0.156 \\
The number of free chain ends & $\mathrm{N} / \mathrm{A}$ & 2 & 142 & 0 \\
\hline
\end{tabular}

In the case of the value of $\mathrm{G}^{\prime \prime}$ at $0{ }^{\circ} \mathrm{C}$, all $\mathrm{LqBR}$ compounds showed lower values than the TDAE compound, which is inferred to be due to the decrease in the $T_{g}$ of the vulcanizates. In addition, as confirmed from the previous Payne effect results, it is considered that all functionalized LqBRs exhibited lower values of $\mathrm{G}^{\prime \prime}$ at $0{ }^{\circ} \mathrm{C}$ than NF-LqBR because the effective filler volume fraction lowered as the silica dispersion was improved.

As shown in Table 10, the value of $\tan \delta$ at $60^{\circ} \mathrm{C}$ showed a tendency to decrease as the number of the free chain ends of LqBRs was decreased. NF-LqBR showed a higher value of $\tan \delta$ at $60^{\circ} \mathrm{C}$ than the TDAE compound because the dangling chain ends after vulcanization of NF-LqBR act as free chain ends. CF-LqBR showed a lower value of $\tan$ $\delta$ at $60{ }^{\circ} \mathrm{C}$ than NF-LqBR, as the chain mobility was decreased by the coupling reaction. However, the value was still higher than that of the TDAE compound because of the free chain ends of both ends. In contrast, OF-LqBR and DF-LqBR showed lower values of $\tan \delta$ at $60{ }^{\circ} \mathrm{C}$ than CF-LqBR because the number of free chain ends was decreased, as the chain ends were fixed to the silica surface. In particular, DF-LqBR showed a lower value than the TDAE compound because the occurrence of hysteresis was the least, owing to the absence of free chain ends. From these results, it is concluded that the effect of the free chain ends of LqBRs is dominant in increasing the values of $\tan \delta$ at $60{ }^{\circ} \mathrm{C}$ in the compounds to which LqBR is applied.

\subsection{The Performance Change of the Compounds}

Table 11 shows the tendency of the change in the physical properties of the compound according to the position of the functional group of LqBRs and the number of free chain ends.

Table 11. Effect of the functional group position of F-LqBR on the performance of silica-filled rubber compounds.

\begin{tabular}{ccccccc}
\hline Types of Processing Aids & Payne Effect & $\begin{array}{c}\text { Extraction } \\
\text { Resistance }\end{array}$ & $\mathbf{M}_{\mathbf{3 0 0}}$ & $\begin{array}{c}\text { Abrasion } \\
\text { Resistance }\end{array}$ & Tan $\boldsymbol{\delta}$ at $\mathbf{6 0}{ }^{\circ} \mathbf{C}$ & $\mathbf{G}^{\prime}$ at $-\mathbf{3 0}{ }^{\circ} \mathbf{C}$ \\
\hline TDAE oil (Reference) & $\mathrm{M}$ & $\mathrm{B}$ & $\mathrm{M}$ & $\mathrm{M}$ & $\mathrm{M}$ & $\mathrm{M}$ \\
\hline NF-LqBR & $\mathrm{M}$ & $\mathrm{M}$ & $\mathrm{B}$ & $\mathrm{G}$ & $\mathrm{W}$ & $\mathrm{G}$ \\
OF-LqBR & $\mathrm{G}$ & $\mathrm{G}$ & $\mathrm{M}$ & $\mathrm{G}$ & $\mathrm{B}$ & $\mathrm{G}$ \\
CF-LqBR & $\mathrm{G}$ & $\mathrm{G}$ & $\mathrm{M}$ & $\mathrm{E}$ & $\mathrm{B}$ & $\mathrm{E}$ \\
DF-LqBR & $\mathrm{E}$ & $\mathrm{E}$ & $\mathrm{E}$ & $\mathrm{G}$ & $\mathrm{G}$ \\
\hline
\end{tabular}

E: Excellent, G: Good, M: Moderate, B: Bad. W: Worst.

\section{Conclusions}

The effects of the functional group position and number of the free chain ends of LqBRs applied as processing aids to silica-filled rubber compounds on the physical properties and hysteresis of the compounds were investigated in this study.

- $\quad$ Payne effect and processability were improved in all functionalized LqBRs without deteriorating the mechanical properties. In particular, CF-LqBR, which has small hydrodynamic volume, showed a lower Payne effect and Mooney viscosity than OF-LqBR. DF-LqBR showed a somewhat high Mooney viscosity owing to the terminal amide and cyano groups.

- $\quad$ NF-LqBR showed a lower delta torque $(\Delta \mathrm{T})$ than the TDAE compounds because of the consumption of sulfur during vulcanization, whereas F-LqBRs showed higher delta torque than NF-LqBR because the functional groups not only were fixed on the 
silica surface, but also formed chemical bonds through a crosslinking reaction with the base polymers.

- The extracted amount of organic matter decreased as the number of functional groups in LqBR was increased.

- The mechanical properties were highly correlated with the crosslink density.

- $\quad T h e T_{g}$ of $L q B R$, as well as the increase in the filler-rubber interaction, are considered as major factors affecting abrasion resistance. As for dynamic properties, snow traction improved as LqBRs lowered the $\mathrm{T}_{\mathrm{g}}$ of the compound. The value of $\tan \delta$ at $60{ }^{\circ} \mathrm{C}$ decreased as the number of the free chain ends of LqBR was decreased.

These characteristics of LqBRs are suitable for winter tires that require high traction and long-term flexibility at low temperatures. In particular, DF-LqBR is a material that can improve fuel efficiency and achieve wear performance simultaneously, and can solve the trade-off problem of tire properties. In brief, DF-LqBR is considered to be an appropriate material for tread compounds of electronic car tires and green tires. In addition, it is expected that the results presented in this study will provide the basis for the optimal LqBR structure design and selection required for the manufacture of tires to which LqBR is applied.

Author Contributions: Data curation, D.K. and B.A.; Formal analysis, H.J. (Hongil Joo) and G.Y.; Investigation, D.K. and B.A.; Methodology, D.K., H.J. (Hongil Joo) and G.Y.; Supervision, W.K.; Validation, H.J. (Heungbae Jeon), H.J.P. and W.K.; Writing—original draft, D.K., H.J. (Hongil Joo) and G.Y.; Writing — review and editing, H.J. (Heungbae Jeon), H.-J.P. and W.K. All authors have read and agreed to the published version of the manuscript.

Funding: This research received no external funding.

Institutional Review Board Statement: Not applicable.

Informed Consent Statement: Not applicable.

Data Availability Statement: Data presented in this study are available upon request from the corresponding author.

Acknowledgments: This work was supported by Hankook Tire \& Technology Co Ltd. and the Ministry of Trade, Industry and Energy Grant funded by the Korean Government (Project Number 20010851), Korea. H.J. also acknowledges Kwangwoon University for supporting his sabbatical year in 2020 .

Conflicts of Interest: The authors declare no conflict of interest.

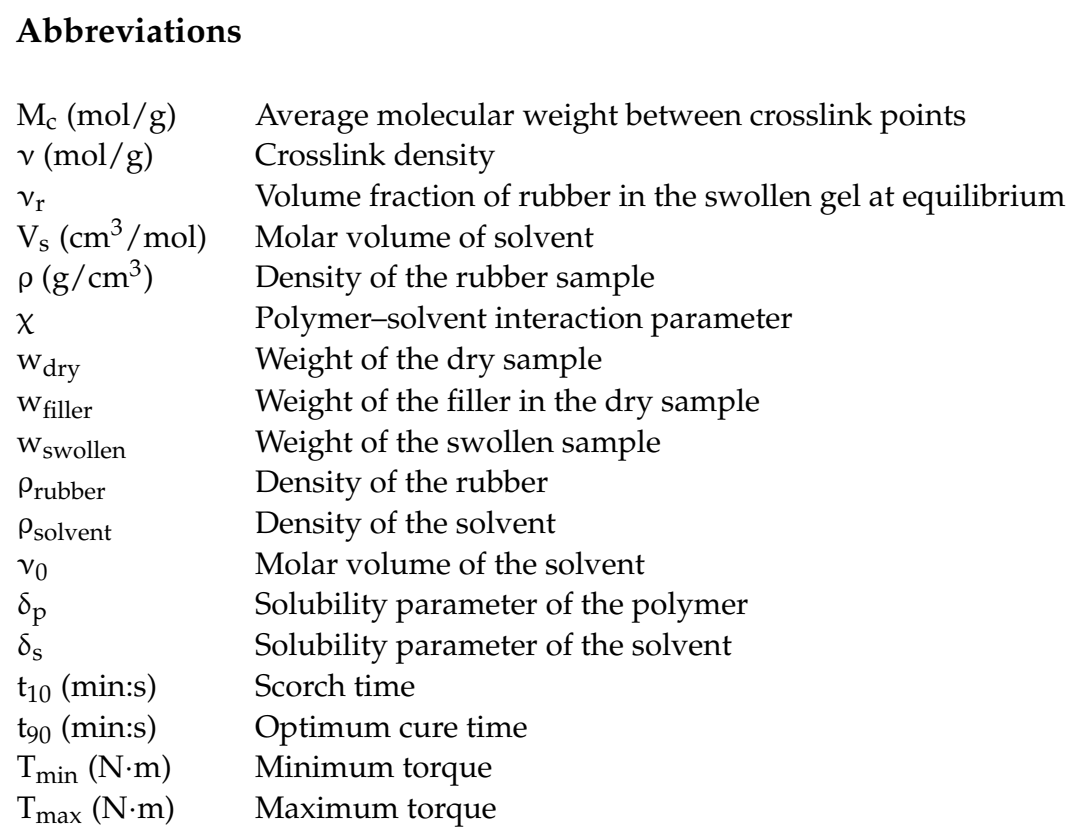




$\begin{array}{ll}\triangle \mathrm{T}(\mathrm{N} \cdot \mathrm{m}) & \text { Delta torque }\left(\mathrm{T}_{\max }-\mathrm{T}_{\min }\right) \\ \mathrm{M}_{100} & \text { Modulus at } 100 \% \text { elongation } \\ \left(\mathrm{kgf} / \mathrm{cm}^{2}\right) & \\ \mathrm{M}_{300} & \text { Modulus at } 300 \% \text { elongation } \\ \left(\mathrm{kgf} / \mathrm{cm}^{2}\right) & \text { Glass transition temperature } \\ \mathrm{T}_{\mathrm{g}}\left({ }^{\circ} \mathrm{C}\right) & \text { Storage modulus } \\ \mathrm{G}^{\prime}(\mathrm{MPa}) & \text { Loss modulus } \\ \mathrm{G}^{\prime \prime}(\mathrm{MPa}) & \text { Tangent delta } \\ \text { Tan } \delta & \end{array}$

\section{References}

1. Gruendken, M.; Velencoso, M.M.; Hirata, K.; Blume, A. Structure-Propery Relationship of Low Molecular Weight "Liquid" Polymers in Blends of Sulfur Cured SSBR-Rich Compounds. Polym. Test. 2020, 87, 106558. [CrossRef]

2. Salort, F.; Henning, S.K. Silane-Terminated Liquid Poly (Butadienes) in Tread Formulations: A Mechanistic Study. Rubber Chem. Technol. 2021, 94, 24-47. [CrossRef]

3. European Union. Directive 2005/69/EC of the European Parliament and of the Council of 16 Nov 2005. Off. J. Eur. Union 2005, 2, 214-217.

4. Ezzoddin, S.; Abbasian, A.; Aman-Alikhani, M.; Ganjali, S.T. The Influence of Non-Carcinogenic Petroleum-Based Process Oils on Tire Compounds' Performance. Iran. Polym. J. 2013, 22, 697-707. [CrossRef]

5. Nakazono, T.; Matsumoto, A. Mechanical Properties and Thermal Aging Behavior of Styrene-Butadiene Rubbers Vulcanized Using Liquid Diene Polymers as the Plasticizer. J. Appl. Polym. Sci. 2010, 118, 2314-2320. [CrossRef]

6. Kataoka, T.; Zetterlund, P.B.; Yamada, B. Effects of Storage and Service on Tire Performance: Oil Component Content and Swelling Behavior. Rubber Chem. Technol. 2003, 76, 507-516. [CrossRef]

7. Gruendken, M. Liquid Rubber for Safer and Faster Tires. In Proceedings of the Tire Technology Expo 2018, Hannover, Germany, 14-16 February 2017.

8. Ikeda, K. Bio Liquid Polymer for Winter Tires. In Proceedings of the Tire Technology Expo 2018, Hanover, Germany, 20-22 February 2018.

9. Hirata, J.K. Effects of crosslinkable plasticizers. RFP Rubber Fibers Plast. Int. 2011, 6, 212-215.

10. Rauline, R. Copolymer Rubber Composition with Silica Filler, Tires Having a Base of Said Composition and Method of Preparing Same. U.S. Patent 5,227,425, 13 July 1993.

11. Hogan, T.E.; Hergenrother, W.L.; Tallman, M. Amine-Containing Alkoxysilyl-Functionalized Polymers. U.S. Patent 8,148,486, 3 April 2012.

12. Hsu, W.L.; Halasa, A.F. Rubbers Having Improved Interaction with Silica. U.S. Patent 5,652,310, 29 July 1997.

13. Taniguchi, K.; Tsukimawashi, K.; Kobayashi, N.; Tadaki, T. Conjugated-Diolefin (co) Polymer Rubber and Process for Producing the Same. U.S. Patent 7,528,199, 5 May 2009.

14. Cray Valley, Technical Data Sheet, Recon. Available online: http:/ / www.crayvalley.com/docs/tds/ricon-603-.pdf?sfvrsn=2 (accessed on 9 April 2018).

15. Evonik. Less Fuel Low. $\mathrm{CO}_{2}$ Emissions with POLYVEST ST Tires. Available online: https://coatings.evonik.com/en/less-fueland-lower-co2-emissions-with-polyvest-st-tires-100233.html (accessed on 13 February 2017).

16. Herpich, R.; Fruh, T.; Heiliger, L.; Schilling, K. Silica Gel-Containing Rubber Compounds with Organosilicon Compounds as Compounding Agent. U.S. Patent 6,593,418, 15 July 2003.

17. Takuya, H.; Tochiro, M.; Sumitomo Rubber Ind. Tire Tread Rubber Composition. U.S. Patent 2,005,146,115, 14 November 2003.

18. Satoyuki, S.; Chikashi, Y.; Yokohama Rubber Co. Ltd. Rubber Composition Containing Compound Having Organosilicon Function Group through Urethane Bond at Terminal. U.S. Patent 2,005,350,603, 22 December 2005.

19. Kim, D.; Ahn, B.; Kim, K.; Lee, J.; Kim, I.J.; Kim, W. Effects of Molecular Weight of Functionalized Liquid Butadiene Rubber as a Processing Aid on the Properties of SSBR/Silica Compounds. Polymers 2021, 13, 850. [CrossRef] [PubMed]

20. Ahn, B.; Park, N.; Kim, D.; Kim, W. Influence of End-Functionalized Solution Styrene-Butadiene Rubber on Silica-Filled Vulcanizates with Various Silica-Silane Systems. Rubber Chem. Technol. 2019, 92, 364-377. [CrossRef]

21. Antkowiak, T.A.; Oberster, A.E.; Halasa, A.F.; Tate, D.P. Temperature and Concentration Effects on Polar-Modified Alkyllithium Polymerizations and Copolymerizations. J. Polym. Sci. A 1 Polym. Chem. 1972, 10, 1319-1334. [CrossRef]

22. Derouet, D.; Forgeard, S.; Brosse, J.C. Synthesis of alkoxysilyl-terminated polyisoprenes by means of "living" anionic polymerization, 1 . Modeling of the termination step by studying the reaction of butyl lithium with various alkoxysilane reagents. Macromol. Chem. Phys. 1998, 199, 1835-1842.

23. Lal, J. Effect of Crosslink Structure on Properties of Natural Rubber. Rubber Chem. Technol. 1970, 43, 664-686. [CrossRef]

24. Mulik, S.; Sotiriou-Leventis, C.; Churu, G.; Lu, H.; Leventis, N. Cross-Linking 3D Assemblies of Nanoparticles into Mechanically Strong Aerogels by Surface-Initiated Free-Radical Polymerization. Chem. Mater. 2008, 20, 5035-5046. [CrossRef]

25. Hoffstetter, J.; Giebeler, E.; Peter, R.; Lutz, P.J. Functionalization of Living Polymers via Ethoxysilane Based Compounds: Synthesis and Interaction with Silica Particles. Macromol. Symp. 2004, 215, 339-352. [CrossRef] 
26. Jones, D.N. (Ed.) Comprehensive Organic Chemistry: Sulphur: Selenium, Silicon, Boron, Organometallic Compounds; Pergamon Press: Oxford, UK, 1979.

27. Patai, S.; Rappoport, Z. The Chemistry of Organic Silicon Compounds; Wiley: New York, NY, USA, 1989.

28. Furin, G.G.; Vyazankina, O.A.; Gostevsky, B.A.; Vyazankin, N.S. Tetrahedron Report Number 234 synthetic aspects of the use of organosilicon compounds under nucleophilic catalysis conditions. Tetrahedron Report Number 234 Synthetic Aspects of the Use of Organosilicon Compounds under Nucleophilic Catalysis Conditions. Tetrahedron 1988, 44, 2675-2749. [CrossRef]

29. Hoffman, R.F.; Gobran, R.H. Liquid Carboxyl-Terminated Poly(Butadiene). Rubber Chem. Technol. 1973, 46, 139-147. [CrossRef]

30. Berenbaum, M.B.; Bulbenko, G.F.; Gobran, R.H.; Hoffman, R.F. Liquid Carboxy-Terminated Polymers and Preparation Thereof with Dicarboxylic Acid Peroxides. U.S. Patent 3,235,589, 15 February 1966.

31. Derouet, D.; Forgeard, S.; Brosse, J. Synthesis of Alkoxysilyl-Terminated Polyisoprenes by Means of'living'anionic Polymerization, 2. Synthesis of Trialkoxysilyl-Terminated 1, 4-Polyisoprenes by Reaction of Polyisoprenyllithium with Various Functional Trialkoxysilanes Selected as End-Capping Reagents. Macromol. Chem. Phys. 1999, 200, 10-24.

32. Ko, Y.H.; Cheen, S.W.; Block, E.-M.S.-D. Copolymer Prepared Using Polyfunctional Coupling Agent. U.S. Patent 6,777,493, 17 August 2004.

33. Liu, X.; Zhao, S.; Zhang, X.; Li, X.; Bai, Y. Preparation, Structure, and Properties of Solution-Polymerized Styrene-Butadiene Rubber with Functionalized End-Groups and Its Silica-Filled Composites. Polymer 2014, 55, 1964-1976. [CrossRef]

34. Payne, A.R.; Whittaker, R.E. Low Strain Dynamic Properties of Filled Rubbers. Rubber Chem. Technol. 1971, 44, 440-478. [CrossRef]

35. Itoh, K. New Functionalized S-SBR Technology to Improve Overall Compound Performance. In Proceedings of the Tire Technology EXPO 2019, Hannover, Germany, 5-7 March 2019.

36. Schreiber, H.P.; Bagley, E.B.; West, D.C. Viscosity/Molecular Weight Relation in Bulk Polymers-I. Polymer 1963, 4, 355-364. [CrossRef]

37. Méndez-Hernández, M.L.; Rivera-Armenta, J.L.; Páramo-García, U.; Corona Galvan, S.; García-Alamilla, R.; Salazar-Cruz, B.A. Synthesis of High cis-1, 4-BR with Neodymium for the Manufacture of Tires. Int. J. Polym. Sci. 2016, 2016, 1-7. [CrossRef]

38. Reuvekamp, L.A.; Ten Brinke, J.W.; Van Swaaij, P.J.; Noordermeer, J.W. Effects of Mixing Conditions-Reaction of TESPT Silane Coupling Agent During Mixing with Silica Filler and Tire Rubber. Kautsch. Gummi Kunstst. 2002, 55, 41-47.

39. Parks, C.R.; Brown, R.J. Crosslink Density of Elastomers. A New Gas-Chromatographic Method. Rubber Chem. Technol. 1976, 49, 233-236. [CrossRef]

40. Hashim, A.S.; Azahari, B.; Ikeda, Y.; Kohjiya, S. The Effect of bis (3-Triethoxysilylpropyl) Tetrasulfide on Silica Reinforcement of Styrene-Butadiene Rubber. Rubber Chem. Technol. 1998, 71, 289-299. [CrossRef]

41. Choi, S.S.; Chung, K.; Nah, C. Improvement of Properties of Silica-Filled Styrene-Butadiene Rubber (SBR) Compounds Using Acrylonitrile-Styrene-Butadiene Rubber (NSBR). Polym. Adv. Technol. 2003, 14, 557-564. [CrossRef]

42. Rattanasom, N.; Saowapark, T.; Deeprasertkul, C. Reinforcement of Natural Rubber with Silica/Carbon Black Hybrid Filler. Polym. Test. 2007, 26, 369-377. [CrossRef]

43. Halasa, A.F.; Prentis, J.; Hsu, B.; Jasiunas, C. High Vinyl High Styrene Solution SBR. Polymer 2005, 46, 4166-4174. [CrossRef]

44. Padenko, E.; Berki, P.; Wetzel, B.; Karger-Kocsis, J. Mechanical and Abrasion Wear Properties of Hydrogenated Nitrile Butadiene Rubber of Identical Hardness Filled with Carbon Black and Silica. J. Reinf. Plast. Compos. 2016, 35, 81-91. [CrossRef]

45. Seo, B.; Kim, K.; Lee, H.; Lee, J.Y.; Kwag, G.H.; Kim, W. Effect of Styrene-Butadiene Rubber with Different Macrostructures and Functional Groups on the Dispersion of Silica in the Compounds. Macromol. Res. 2015, 23, 466-473. [CrossRef]

46. Derham, C.F.; Newell, R.; Swift, P.M. The Use of Silica for Improving Tread Grip in Winter Tyres. NR Technol. 1988, 19, 1-9.

47. Dörrie, H.; Schröder, C.; Wies, B. Winter Tires: Operating Conditions, Tire Characteristics and Vehicle Driving Behavior. Tire Sci. Technol. 2010, 38, 119-136. [CrossRef]

48. Hirata, K.; Moriguchi, M. Bio-Based Liquid Rubber for Tire Application. Rubber World 2017, 256, 50-55.

49. Wang, M.-J. Effect of Polymer-Filler and Filler-Filler Interactions on Dynamic Properties of Filled Vulcanizates. Rubber Chem. Technol. 1998, 71, 520-589. [CrossRef]

50. Han, S.; Kim, W.S.; Mun, D.Y.; Ahn, B.; Kim, W. Effect of Coupling Agents on the Vulcanizate Structure of Carbon Black Filled Natural Rubber. Compos. Interfaces 2020, 27, 355-370. [CrossRef]

51. Kitamura, T.; Lawson, D.F.; Morita, K.; Ozawa, Y. Anionic Polymerization Initiators and Reduced Hysteresis Products Therefom. U.S. Patent 5,393,721, 28 February 1995. 